\title{
ELECCIONES AL PARLAMENTO VASCO DE 13 DE MAYO DE 2001: ¿UNAS ELECCIONES SORPRENDENTES?
}

\author{
LAURA RUIZ DE GALARRETA \\ Profesora Asociada de Periodismo Político \\ de la Facultad de Comunicación \\ Universidad de Navarra \\ CARLOS VIDAL PRADO \\ Profesor Asociado del Departamento de \\ Derecho Constitucional de la UNED
}


SUMARIO

1. UnA CONVOCATORIA MARCADA POR EL ENFRENTAMIENTO SOCIAL, POLITICO Y MEDIÁTICo.- 2. La CAMPAÑA Electoral. 2.1. UNA POLARIZACIÓN INEVITABle. 2.2. LoS MENSAJES DE LOS PARTIDOS: LA INSTRUMENTALIZACIÓN DEL MIEDO. 2.3. LA LLAMADA A LA PARTICIPACIÓN. 2.4. DIVERSIDAD DE ENCUESTAS Y DUDOSA CREDIBILIDAD.- 3. LAS ELECCiones del 13 de mayo. 3.1. Resultados globales. 3.2. Resultados por Territorios Históricos. 3.3. El Voto de LAS CAPITALES EN CONTRASTE CON EL DEL Resto de los Territorios Históricos.- 4. Algunas claves en los resultados de VITORIA Y ÁlaVA.- 5. CONCLUSIONES: LA TAREA PENDIENTE DE RECUPERAR LA LIBERTAD. 


\title{
ELECCIONES AL PARLAMENTO VASCO DE 13 DE MAYO DE 2001: ¿UNAS ELECCIONES SORPRENDENTES?
}

\author{
POR \\ LAURA RUIZ DE GALARRETA \\ Profesora Asociada de Periodismo Político de la Facultad \\ de Comunicación. Universidad de Navarra \\ CARLOS VIDAL PRADO \\ Profesor Asociado del Departamento de \\ Derecho Constitucional de la UNED
}

\section{UNA CONVOCATORIA MARCADA POR EL ENFRENTAMIENTO SOCIAL, POLÍTICO Y MEDIÁTICO.}

Desde el final de la tregua, la situación del Gobierno de Ibarretxe fue haciéndose cada vez más insostenible. La apuesta que el PNV habia concretado en el Pacto de Estella suponía una ruptura de la situación que hasta ese momento se había vivido en la política vasca. La división no era tanto la que se daba entre nacionalistas y no nacionalistas, sino entre violentos $y$ no violentos: todos los partidos democráticos, por encima de sus ideologías, estaban de acuerdo en la lucha frente a ETA, y en desarrollar la acción política en el marco de la Constitución y el Estatuto. Hasta ese momento se habían dado incluso varios gobiernos de coalición entre PSE y PNV. 
Sin embargo, esta línea divisoria cambió con el Pacto de Estella. EI PNV y EA optaron por invertir su estrategia. Por un lado, el pacto se firmó con $\mathrm{HB}$ y con sectores radicales abertzales, e incluso se firmaron documentos con ETA. Por otro lado, para poder ponerse de acuerdo, el PNV tuvo que dar un paso más en sus reivindicaciones políticas hacia Madrid, abandonando el marco estatutario y optando por lo que se ha venido a llamar "soberanismo". EI PNV justificaba su nueva actitud en la necesidad de acercar las posiciones de los violentos hacia las de los partidos democráticos, y, fundamentalmente, lograr que ETA dejase las armas, al menos temporalmente: "Si se le da un cauce político de actuación, y si se apoyan algunas de sus reivindicaciones -pensaban los dirigentes del PNV y EA-, quizá logremos un compromiso de abandono de las armas".

La primera consecuencia política de la firma del Pacto fue la salida del Gobierno por parte del PSE. Era una muestra evidente de que la senda iniciada por los nacionalistas les empezaba a distanciar claramente de los demás partidos no nacionalistas, excepto de IU, que, sorprendentemente, firmó el Pacto de Estella y se mantuvo en él a pesar de los problemas internos. Otra consecuencia, sin duda más importante de cara a la sociedad española y vasca, fue que, efectivamente, ETA estableció un período de tregua. La cuestión era comprobar si ésta sería provisional o podría convertirse en definitiva. $Y$ también si la voluntad de los terroristas era sincera o no. La presión policial en los últimos meses había sido muy notable, y el grupo terrorista estaba en un momento delicado, en el que incluso desde el punto de vista estratégico le interesaba una tregua para reorganizarse.

En estas circunstancias se celebraron las anteriores elecciones autonómicas, en las que se produjo un notable incremento del voto de HB (hasta ese momento siempre descendente), y la victoria del PNV junto con el ascenso del PP, mientras que el PSE mantenía su nivel de respaldo electoral ${ }^{1}$.

A la luz de los resultados de las autonómicas del 98, el PNV necesitaba los votos de algún otro partido para poder gobernar: con 21 escaños sobre 75 era necesario llegar a acuerdos. Puesto que se había firmado el Pacto de Estella, resultaba lógico pactar con los otros partidos firmantes, desde el punto de vista de la estrategia iniciada por los nacionalistas. Así, el primer acuerdo se firmó con EA,

1 Vidal Prado, Carlos, "Elecciones al Parlamento Vasco de 27 de octubre de 1998", en Revista de Derecho Político, núm. 44, pp. 401-419. 
que, como había hecho en otras ocasiones, se mostró dispuesto a integrarse en el gobierno. Con EH (el nuevo nombre electoral con el que HB pretendía suavizar su imagen) se alcanzó un pacto de apoyo en la investidura y en el Parlamento, aunque la formación abertzale no llegó a entrar en el Gobierno. Se consumaba así una estrategia de frente común nacionalista ante los partidos no nacionalistas. Comenzaba una época de "frentes", y no precisamente por iniciativa de PP y PSE sino del PNV, aunque éste intentase luego en múltiples ocasiones culpar de ello al PP.

La "unidad de acción» de los nacionalistas funcionó mientras duró la tregua de ETA. Pero la banda terrorista, probablemente sorprendiendo incluso a $\mathrm{EH}$, anunció el fin de la tregua apenas transcurrido un año desde la convocatoria electoral, amparándose en un supuesto incumplimiento de los plazos acordados por parte de PNV y EA. En ese momento, el Gobierno vasco se distanció aparentemente de EH, aunque no llegó a quedar claro si hubo o no una ruptura formal del pacto de legislatura. EH dejó de ir regularmente al Parlamento, y el Gobierno quedó en minoría. A pesar de que el PSE le aseguró su apoyo si renunciaba al camino iniciado en Estella, el PNV no aceptó su ofrecimiento, y comenzó una época de inestabilidad que duró muchos meses.

La inoperancia del Gobierno y Parlamento vascos, junto a la falta de claridad en los planteamientos de PNV y EA ante la violencia y el terrorismo, provocó que la brecha entre nacionalistas y no nacionalistas fuese cada vez mayor. Además, algunos atentados terroristas contra destacados dirigentes de ambos partidos en Euskadi, especialmente el asesinato de Fernando Buesa, socialista y ex-vicepresidente del Gobierno vasco, contribuyeron a ahondar más las diferencias, ante la pasividad del PNV y EA: la condena formal de los atentados no se veía acompañada de una actitud clara en las iniciativas políticas concretas. Parecía, y así lo afirmaron algunos líderes políticos, que para que el PNV rompiera sus lazos con EH hacía falta un número determinado de muertes o que los terroristas apuntaran a objetivos de especial relevancia política.

Las elecciones generales de 2000 situaron al PP empatado con el PNV en número de escaños, y muy cercano en número de votos. Los diputados logrados por el PP más el PSOE superaban los diputados obtenidos por los grupos nacionalistas, y esto hizo quizá suponer a ambos partidos que la alternativa al nacionalismo era factible, con lo cual se intensificó su oposición en el Parlamento.

La distancia entre los nacionalistas y los llamados «constitucionalistas" se incrementó hasta el punto de que PP y PSE presentaron 
sendas mociones de censura en la Cámara vasca. El objetivo era doble: por un lado, poner de relieve la soledad de lbarretxe en el Parlamento y su incapacidad para emprender nuevas iniciativas políticas; por otro, obligarle a recurrir al apoyo de EH, el mismo apoyo que él afirmaba rechazar desde hacía unas semanas. Las mociones de censura evidentemente no prosperaron, aunque los votos a favor fueron más que los votos en contra, puesto que Euskal Herritarrok no apoyó a lbarretxe.

Si la tensión en los foros políticos iba en aumento, algo muy parecido sucedía en la sociedad vasca. Uno de los fines del Pacto de Estella fue amortiguar los efectos del "Espíritu de Ermua", la gran movilización social que se produjo como consecuencia del rechazo social al secuestro y asesinato del concejal del PP, Miguel Ángel Blanco, en julio de 1997. El nacionalismo vasco consiguió neutralizar la oleada de solidaridad e indignación popular gracias a la proclamación de la tregua por parte de ETA. Éste fue, desde el punto de vista social, el elemento más rentable del Pacto de Estella.

Con la ruptura de la tregua, la sensibilización social se incrementó de nuevo y resurgió la movilización contra ETA. Los primeros atentados en la nueva etapa de actividad terrorista fueron seguidos de multitudinarias manifestaciones ciudadanas. Sin embargo, en esta ocasión, la movilización contra el terrorismo no unió a nacionalistas y no nacionalistas. Al contrario, sirvió para ahondar las diferencias entre ellos. La prueba más evidente fue la manifestación que tuvo lugar en Vitoria el 26 de febrero de 2000 , el sábado posterior al asesinato de Fernando Buesa y de su escolta, Jorge Díez. Los titulares de los periódicos fueron reveladores en este mismo sentido ( 100.000 vascos se manifiestan contra ETA divididos por el papel de lbarretxen)2.

Las sucesivas concentraciones de condena de la actividad terrorista que tuvieron lugar en los meses posteriores reflejaron también esta misma división: grupos separados en las manifestaciones, diferentes lemas y convocatorias, gritos contra ETA mezclados con gritos "pro" y "anti» nacionalistas... La movilización social se articuló además en algunos colectivos liderados por intelectuales y destacadas personalidades del ámbito cultural vasco. Además del Foro de Ermua, constituido con motivo del asesinato de Miguel Ángel Blanco, nació un nuevo movimiento con el lema "Basta Ya», que encontró en el filósofo Fernando Savater su más firme baluarte.

2 Artículo de Josean Izarra en El Mundo, domingo, 27 de febrero de 2000. 
Ésta era la primera vez que personas no vinculadas a la política se manifestaban abiertamente contra la ambigüedad de los nacionalistas y la pretendida equidistancia entre los terroristas y los partidos defensores de la Constitución y el Estatuto. La presencia de estas plataformas y otras como Víctimas del Terrorismo en la opinión pública fue muy intensa - con numerosos actos públicos e innumerables artículos en las secciones de opinión de los periódicos-y tuvo una clara influencia en la campaña. Existía una cierta sensación de que podía estar produciéndose un cambio social, en el sentido de que personas que no habian exteriorizado hasta ese momento de modo claro su opinión comenzaron a hacerlo ${ }^{3}$.

El ejemplo de personalidades relevantes podría generar un "efecto llamada" entre los ciudadanos, como pareció ponerse de relieve en el acto de apoyo que convocó Basta Ya en San Sebastián el primer domingo de la campaña, que congregó a más de diez mil ciudadanos en defensa de la Constitución y el Estatuto, y contra ETA. Se trataba de la primera manifestación multitudinaria en el País Vasco que no contaba con el respaldo del nacionalismo, al menos desde el punto de vista institucional.

Los medios de comunicación contribuyeron, tanto a nivel nacional como en Euskadi, a radicalizar las posturas. Quizá fue especialmente dura y agresiva la actitud de los medios nacionales que, desde Madrid, parecían lejos de comprender a fondo el problema tal como se veía en el propio País Vasco. Esta "toma de postura" por parte de muchos medios de comunicación ha suscitado, con posterioridad a las elecciones, un intenso debate. Sin duda, sólo la sensación de estar ante un nuevo 1977, en el sentido de creer "en juego la libertad de un pueblo y de cada uno de sus componentes"'4, llevó a los periodistas a tomar partido de forma tan clara y activa por una opción electoral.

Pero, además, el cambio social parecía también avalado por los resultados de algunas encuestas. Por ejemplo, el Euskobarómetro (encuesta realizada periódicamente por el Departamento de Ciencia Política de la UPV) del mes de diciembre de 2000 revelaba que un 50\% de los vascos votaría a favor de la Constitución (frente al $31 \%$ que lo hizo en el 78). Incluso cuatro de cada diez vascos apoyaban el actual modelo autonómico, respaldado sin reservas por los votantes del PP y

3 Alentaban esta tesis del posible cambio social Uriarte y Ruiz BuJedo en: URIARTE, E. Y RuIz BuJedo, C., "Elecciones autonómicas vascas: ¿cambio o continuidad?», en Cuadernos de Alzate, número 23, 2001.

4 Sinova, Justino, "El cambio es posible», El Mundo de 13 de mayo de 2001. 
PSE y por un tercio del electorado del PNV5. Otra encuesta del CIS, realizada en febrero de 2001, reflejaba un retroceso del sentimiento nacionalista con relación a 1978, asi como una adhesión creciente a las instituciones autonómicas (58,9\% frente al $23,9 \%$ que defiende el derecho de secesión), datos ambos coincidentes con los resultados del Euskobarómetro realizado en las mismas fechas 6 .

Estas mismas encuestas ponian de manifiesto que seguia existiendo miedo entre los ciudadanos vascos. Miedo a expresar sus ideas en un entorno nacionalista dominante. Miedo a la actividad terrorista y a la violencia callejera. Desconfianza en el futuro y una percepción muy negativa de la situación política?. Todo ello paradójicamente acompañado de una alta satisfacción con el nivel de vida y la situación económica.

En el seno del nacionalismo se agravaron algunas discrepancias que ya se venían manifestando en los últimos años. Las declaraciones públicas de destacados militantes como Emilio Guevara o José Ángel Cuerda, incluso de diputados autonómicos como Joseba Arregui, se convirtieron en habituales, lo cual permitía pensar que dentro del PNV se podían estar formando diversas corrientes disconformes con la línea oficial. Desde estos sectores nacionalistas moderados se cuestionaba la postura poco clara del Partido Nacionalista Vasco en relación con la violencia ${ }^{8}$, así como el abandono del discurso legitimatorio de la realidad estatutaria ${ }^{9}$. Sin embargo, cada una de las críticas fue debidamen-

5 El Mundo, sábado, 15 de enero de 2000.

6 El País, domingo, 21 de marzo de 2001.

7 Uriarte, Edurne. "El miedo no declarado», $A B C$ de 29 de julio de 2000.

8 Arregui planteaba el riesgo de confundir nacionalismo con violencia: "La inexistencia de límites para el diálogo es una forma indirecta de decir que, para que el proceso de paz resulte, es preciso saltar la frontera que deslinda la democracia de la no democracia, porque quienes han aceptado el resultado de todas las elecciones, incluida la de refrendo del Estatuto, los que han jugado según las reglas del juego de la democracia, deben dejar en suspenso su existencia histórica, institucional y jurídica, para dar paso a un juego en el que también puedan jugar los violentos". Cfr. ArRegUl, J., La nación vasca posible. El nacionalismo democrático en la sociedad vasca, Crítica, Barcelona, 2000, p. 52.

9 “Al fallar en el desarrollo de un discurso legitimatorio de la realidad estatutaria, el nacionalismo democrático ha fallado en el primer requisito para hacer frente a la violencia: la barrera de la realidad institucional y de su legitimidad. A falta de esa barrera, las fronteras se vuelven fluidas, borrosas, y el riesgo de desintegración social aumenta", Cfr. ARregUl, J., La nación vasca posible. El nacionalismo democrático en la sociedad vasca, op. cit., p. 98 . Sobre el acercamiento a las posiciones de los violentos, acompañado de lo que se considera una "claudicación ideológica" por parte del PNV con relación a HB y ETA, se venía manifestando desde hace años, en tono crítico, algún sector del PNV, muy vinculado a los oríge- 
te valorada y descalificada por los portavoces oficiales, hasta el punto de que los críticos fueron considerados por Arzallus como los "michelines" del partido.

Los indicios sociales y políticos hacían pensar en la posibilidad cierta de una alternancia en el poder. El Pacto de Estella unió, sin ellos pretenderlo, al PSE y PP en la configuración de una alternativa política al nacionalismo, caracterizada en la defensa y mantenimiento del marco constitucional y estatutario. Esta unión generó una presión de estos dos partidos sobre el lehendakari, reclamando la disolución del Parlamento y la convocatoria de nuevas elecciones, de modo que se pusiese fin a la situación de bloqueo que se estaba viviendo. Sin duda, PP y PSE creían en una posibilidad real de victoria en las elecciones. Quizá en el seno del PNV se pensó también en un probable fracaso electoral y, aunque sus dirigentes no llegaron nunca a exteriorizarlo claramente, algunas alusiones veladas que realizaron en la campaña electoral así parecían demostrarlo. Sin embargo, la negativa a la exigencia de la convocatoria electoral se basaba, según los nacionalistas, en que no supondría grandes cambios en la composición política del Parlamento vasco.

En todo caso, la presión llegó a tal extremo que Juan José Ibarretxe no tuvo más remedio que disolver el Parlamento y convocar elecciones. El deterioro de la situación, el bloqueo de la actividad parlamentaria, y la cada vez mayor radicalización de las diferencias hicieron claudicar al Presidente vasco. Sin embargo, la convocatoria de las elecciones fue atípica: Ibarretxe anunció en rueda de prensa que disolvería la Cámara... jun mes después!, de modo que el Parlamento siguió en el ejercicio de su mandato sabiendo que le quedaban cuatro semanas de vida. Esta peculiar forma de anunciar la disolución provocó el rechazo de los partidos de la oposición, y abrió anticipadamente el período de precampaña, mucho más largo de lo habitual.

La legislatura quedó finalmente "abortada por la política de adversarios (frentes o bloques), que ha fracturado gravemente la vida social y política del País Vasco" ${ }^{10}$. Las nuevas elecciones planteaban la opción entre cambio o continuidad ${ }^{1}$, no sólo desde un punto de vista político sino de mayoría de gobierno.

nes del partido. Cfr. Irala, A. de, Escritos políticos sobre la situación vasca 19841985, Burujabetzaren Alde, 1986, pp. 11 y ss.

10 Llera Ramo, F.J., "Cambio político en Euskadi: Entre Lizarra y AjuriaEnea", en Temas para el Debate, julio 2001, núm. 80, p. 56.

11 URIARTE, E. y Ruiz BuJedo, C., «Elecciones autonómicas vascas: ¿cambio o continuidad?", en Cuadernos de Alzate, número 23, 2001. 


\section{LA CAMPAÑA ELECTORAL.}

\subsection{Una polarización inevitable.}

La polarización entre nacionalistas y no nacionalistas se puso de manifiesto también en la campaña. EI PNV, que ya había firmado un pacto electoral con EA para las elecciones municipales de 1999, hizo lo propio en esta ocasión. Temían los dirigentes nacionalistas que el avance del PP podía llegar a convertirlo en la primera fuerza política del País Vasco, y uniendo sus votos a los de EA, pretendía neutralizar este riesgo.

Por otro lado, el PP y el PSE se manifestaron públicamente dispuestos a articular una alternativa de gobierno conjunta. Su prioridad principal sería la recuperación de un espacio de libertad en el País Vasco, esgrimiendo como ejes fundamentales una mayor eficacia en la lucha antiterrorista y la revisión del modelo educativo vasco para evitar la manipulación de los jóvenes. En Álava, el PP pactó con UA, ya desde mediados de marzo, buscando aglutinar el mayor número posible de apoyos $y$ presentando el acuerdo como un "reencuentro" con ambición de estabilidad que acreditaba la solidez de la alternativa.

Estas elecciones pasarán a la historia como las del reagrupamiento del nacionalismo democrático en torno a lbarretxe, aunque, sin duda alguna, se trataba de un movimiento defensivo ante la posibilidad de perder. Pero este reencuentro provocó el silenciamiento de las voces de EA, y elevó la del lehendakari. En el otro bloque, Jaime Mayor ocupó un papel mucho más destacado que el de Nicolás Redondo, puesto que parecía claro que los resultados del PP iban a ser mejores que los del PSE, y que Mayor sería lehendakari si los partidos constitucionalistas lograban vencer en las elecciones. Los nacionalistas aprovecharon mucho este hecho en su campaña, haciendo hincapié en un hipotético seguidismo del PSE hacia el PP, y presionando intensamente a Redondo para que abandonase su posición común en las cuestiones esenciales.

Así pues, las dos voces fundamentales de la campaña eran la de Juan José Ibarretxe, por parte de PNV-EA, y la de Jaime Mayor Oreja, por el PP, y casi podría decirse que también por el Partido Socialista. Ambos candidatos representaban las dos alternativas políticas principales.

Izquierda Unida se mantuvo en la postura de equidistancia que venía sosteniendo desde su apoyo al Pacto de Estella, mucho más cer- 
cana a las posiciones nacionalistas que a la de los partidos nacionales. Había recibido también algunos guiños por parte del PNV, como fue la modificación a la baja de la barrera electoral desde el 5 al $3 \%$, medida de la que, en un principio y antes de su acuerdo con el Partido Popular, también pretendía beneficiarse Unidad Alavesa.

Euskal Herritarrok, por su parte, se presentaba a las elecciones en circunstancias muy desfavorables. Si en las autonómicas de 1998 había experimentado una mejora en sus resultados gracias a la tregua, ahora, en medio de una escalada terrorista, parecía bastante evidente el abandono de algunos de sus votantes, especialmente de aquéllos que en las generales apoyaron al PNV ante la petición de abstención de los radicales.

\subsection{Los mensajes de los partidos: la instrumentalización del miedo.}

La campaña electoral vasca comenzó oficialmente el 26 de abril, a las doce de la noche. Sin embargo, en esta ocasión, la tradicional pegada de carteles del jueves, 26 , sólo marcó el comienzo del aumento en la intensidad de una campaña que ya se había iniciado tiempo atrás, prácticamente desde la convocatoria de elecciones por parte del lehendakari un mes antes.

EI PP se lanzaba a la carrera electoral con un objetivo claro: el apoyo incondicional de sus votantes fieles estaba garantizado, y debia apostar por atraer el voto de los nacionalistas moderados, especialmente los de las ciudades de más de $\mathbf{5 0 . 0 0 0}$ habitantes, dando garantías de que un hipotético Gobierno vasco liderado por los constitucionalistas no significaría un retroceso de la cultura y la economía vascas, del autogobierno, ni un incremento de la actividad terrorista.

EI PNV, en coalición con Eusko Alkartasuna, consciente por primera vez en unas elecciones vascas de sus posibilidades ciertas de perder, debía aglutinar todos los votos que se desprendían de EH por la escalada terrorista de los últimos tiempos, y, a la vez, mantener y consolidar el apoyo de todos sus votantes - nacionalistas moderados y los radicales-.

EI PSE se lanzó a buscar un espacio propio que le llevó incluso a solicitar públicamente al PP que no hablara de los dos partidos como si de una coalición se tratara. Ambas formaciones mantenían unos principios básicos en común - plasmados en un pacto de colaboración, el Pacto por la Libertad y contra el Terrorismo, a nivel nacional-, 
pero el PSE pretendía mantener al margen sus propuestas progresistas de gestión, que lo distanciaban ideológicamente del PP y le aseguraban los votos de los sectores más industrializados del País Vasco, sus feudos tradicionales.

Los dos partidos minoritarios -al concurrir en solitario a las elecciones- tenian un papel muy difícil. Izquierda Unida se presentaba en la campaña con la necesidad de "explicar lo inexplicable», al menos desde el punto de vista de la política nacional: cómo un partido de siglas nacionales se había involucrado en Estella, cómo había apoyado un gobierno nacionalista que se había constituido con el apoyo de $\mathrm{EH}$, cómo se había beneficiado de la gestión y la capacidad legislativa (modificación de la ley electoral rebajando la barrera del 5 al $3 \%$ ) de un gobierno "de derechas". ¿Cómo neutralizar el descalabro electoral a nivel nacional que podría suponer este curriculum en la gestión vasca? Y, lo más difícil, ¿cómo defenderlo en una campaña electoral sin herir de muerte a Izquierda Unida en el resto de España?

La postura de Izquierda Unida-Ezker Batua en estas elecciones continuó por tanto con la línea marcada por su principal dirigente, Javier Madrazo, que había apostado por la vía de Estella de una forma casi personal. IU no respondió en la campaña a las cuestiones que se acaban de plantear y quizá en este "silencio" radicó su mayor acierto. Madrazo desistió de "explicar lo inexplicable" e intentó mantenerse al margen de la estrategia frentista, aunque se posicionó más cerca de los nacionalistas que de los constitucionalistas, atacando, de forma especialmente agresiva, la figura de Jaime Mayor con su lema "Órdago a Mayor".

$\mathrm{EH}$, por su parte, se veía fuertemente condicionado por la actividad terrorista, que indudablemente le haría perder muchos votos. La tregua había creado una corriente a su favor en los anteriores comicios, como también en esta ocasión la ferocidad de la ofensiva etarra desde el final del período de tregua suponía una corriente en contra.

Las campañas de Euskal Herritarrok, que siempre destacan por la originalidad de su puesta en escena, habían conseguido hasta entonces convertir la coalición en protagonista de las sucesivas campañas. En esta ocasión, a pesar de la procacidad de sus carteles electorales -el torso desnudo de una mujer embarazada que simbolizaba el nacimiento de Euskal Herria-, no consiguieron neutralizar la sensación de que era un partido en claro descenso.

Aun conscientes de estas perspectivas poco optimistas, los radicales abertzales se lanzaron a la campaña con el objetivo de convertir- 
se en la "llave" de la política vasca tras el 13 de mayo, centrando sus críticas en el Gobierno español y en el lehendakari, al que acusaban de ser "representante ordinario del Estado español en las Vascongadas" y descalificaban por "su cobardía y carácter débil", mientras se presentaban como "los socialistas de Euskal Herria».

Así las cosas, la campaña comenzó con un ritmo intenso $y$, como comentaba algún columnista de la prensa nacional, mediatizada por "los estigmas del fracaso de Ibarretxe». En esta ocasión, todos los partidos esgrimieron el «miedo al contrario» como eje fundamental de sus mensajes: el PNV, PP, PSE, IU, incluso EH.

EI PNV dejó desde el principio clara su intención de polarizar la campaña entre Ibarretxe y Mayor Oreja y de vincular la imagen de Mayor al "Gobierno de Madrid", tratando de suscitar así el miedo de las bases a una hipotética invasión española, mientras descalificaba el seguidismo de Nicolás Redondo hacia el PP, como ya ha sido apuntado.

Precisamente, la ausencia de debates cara a cara entre los candidatos en estas elecciones se debió a ese intento del PNV de ningunear al candidato del PSE, Nicolás Redondo. Después de poner muchas objeciones y numerosos condicionantes, Juan José Ibarretxe lanzó un reto a Mayor Oreja el sábado anterior al comienzo oficial de la campaña: se enfrentaría a él - Jaime Mayor-y sólo a él en un cara a cara, con un formato, una fecha y un lugar ya predeterminados. El motivo aducido para no invitar al candidato socialista era que "la voz de Nicolás Redondo es la misma que la del candidato popular y sus propuestas, coincidentes".

Si bien este gesto suponía una prueba más de su poca confianza en los resultados de las elecciones, puesto que son los candidatos de la oposición los que acostumbran a retar a los candidatos de los partidos en el Gobierno, la propuesta de lbarretxe iba envenenada, porque, al excluir a Nicolás Redondo, colocaba en una situación muy delicada a los candidatos socialista y popular. Un «no» a la propuesta nacionalista sería difícil de justificar (Jaime Mayor sería acusado de uarredrarse por miedo" a un fracaso seguro), y una respuesta afirmativa pondría en peligro el pacto con el PSOE, que ya habia exigido la presencia de Redondo en el debate.

Finalmente, $y$ tras una primera respuesta un tanto precipitada por parte de las filas populares, Jaime Mayor renunció al cara a cara porque el lehendakari en funciones no reconsideró la presencia de Redondo en el debate. 
Otra de las bazas que supo jugar muy bien el PNV que la del victimismo $y$, en este sentido, los nacionalistas realizaron una puesta en escena en la que los papeles estaban intencionadamente repartidos. Así, mientras Arzallus hacía gala de su habitual audacia verbal con las más desabridas descalificaciones dedicadas al candidato popular («En caso de llegar al Gobierno, no gobernará desde Ajuria Enea, sino desde Intxaurrondo", "Viene con la porra en una mano y la gorra de ministro en la otra"...), lbarretxe ejercía un papel más moderado, convirtiéndose en la "víctima de las víctimas" en una auténtica pirueta de imagen. El momento cumbre tuvo lugar tras el atentado que acabó con la vida del presidente del PP aragonés, Manuel Giménez Abad, cuando el entonces lehendakari en funciones acudió por primera vez al funeral de un miembro del PP fuera del País Vasco y, a la salida de la iglesia, fue abucheado con gritos de "asesino", "cómplice" y "kanpora", mientras los medios nacionales descalificaban el gesto por electoralista. La imagen que ofreció lbarretxe aquella tarde quedó sin duda grabada en la memoria de muchos votantes como la del desprecio de los «españoles» hacia el Presidente de todos los vascos.

EI PNV supo cambiar el punto de vista de su batalla política en los meses previos a la convocatoria electoral. No se habló tanto del soberanismo, como cuando se firmó Estella, sino que se recurrió a las emociones y los sentimientos. Se hizo especial hincapié en la sensación de progreso económico, y se intentó convencer a los ciudadanos de que si querian defender sus raíces, debían apoyar al nacionamismo moderado ${ }^{12}$.

La campaña del PP, y la del PSE, contribuyeron, por tanto, a hacer de Ibarretxe y de los nacionalistas las "víctimas», y eso movilizó mucho voto nacionalista que se sintió de alguna forma agredido. Los votantes no creyeron en el miedo que trataban de potenciar PP y PSE: miedo a Estella, a futuros pactos con EH..., que se vio hábilmente desactivado por el mensaje moderado del candidato nacionalista en los últimos días de la campaña, cuando también Arzallus pasó a un estratégico segundo plano. En cambio sí creyeron en el miedo que predicaba el PNV (miedo a Jaime Mayor, a un Gobierno vasco dirigido desde Madrid, a la erradicación de la cultura vasca, a una actividad más intensa de ETA...). Si a esto añadimos la fuerte penetración social que tiene el PNV en Euskadi, que le permite transmitir su mensaje de forma directa, familiar y fuera de los cauces institucionales, es más fácil llegar a entender por qué su campaña resultó mucho más efectiva que la del PP o el PSOE.

12 WERT, J.I., "País Vasco: Otro punto de vista. Lo que aún no se ha dicho", en Nueva Revista, julio-agosto 2001, pp. 14-15. 
La campaña de Jaime Mayor Oreja parecía transmitir un sentimiento pesimista al electorado, frente a la imagen de normalidad, del "aquí se vive de maravilla", que trasladaba Ibarretxe. El empeño de Jaime Mayor en "despertar" y "movilizar" la conciencia de los ciudadanos vascos terminó quizá por convertir al candidato popular en el rostro y la encarnación del "mensaje negativo". En cambio, en el caso de Ibarretxe sucedía lo contrario: el candidato del PNV se convirtió en la imagen del "mundo que queremos", alejado de la idea de enfrentamiento social que podía empañar la campaña de los constitucionalistas.

El programa del PP pasó inadvertido en la campaña: parecía que sólo se hablaba de la necesidad de acabar con el terrorismo, sin llegar a calar en los votantes cuáles eran las propuestas del PP en otros ámbitos. En este sentido, el mensaje del PP no consiguió ilusionar al electorado, y la posibilidad de que Jaime Mayor fuese lehendakari se relacionó con un aumento de la tensión e incluso de la actividad terrorista, idea propiciada también por el aparato propagandístico del PNV. Los populares no lograron transmitir una imagen de partido de gobierno, con alternativas concretas en materia económica, social, educativa, sanitaria, etc.

Por otra parte, si bien Pablo Mosquera (el líder de Unidad Alavesa), una vez llegado el acuerdo con el PP, se mantuvo en un segundo plano, la incorporación de UA no moderó el mensaje del PP vasco en la campaña, sino más bien al contrario. De este modo, la sensación que quizá se extendió en una buena parte del electorado fue la de que en el lado nacionalista podían encontrar moderación y continuidad, mientras que la otra alternativa ofrecía un planteamiento rupturista $y$ de incierto futuro.

EI PSE, fiel a sus planteamientos, se dedicó a defender su pacto con el PP en las cuestiones esenciales - fundamentalmente el terrorismo y la exigencia de un espacio de libertad- y a presentar una opción de gestión de centroizquierda que lo diferenciara de los populares. Sin embargo, su postura suscitó la aparición de voces discrepantes en un partido en el que algunos líderes territoriales cuentan con un peso decisivo. Así, un elemento significativo de la campaña del PSE fue la firmeza con la que los socialistas vascos debieron mantener su postura ante el nacionalismo, cuestionada, en ocasiones, por personajes de la talla de Pascual Maragall o Felipe González y, en el propio PSE, por Odón Elorza. La labor tenaz de dirigentes del Partido Socialista del País Vasco como Nicolás Redondo, Rosa Díez o el alavés Javier Rojo -que contó con el apoyo expreso de José Luis Rodríguez Zapatero- equilibró las posibles ambigüedades que podían percibirse en el mensaje socialista. 


\subsection{La Ilamada a la participación.}

Se ha dicho que la campaña electoral "ha sido decisiva como pocas y que sirvió para movilizar masivamente ${ }^{13}$ a la sociedad vasca y española. Lo segundo es evidente, pero lo primero no tanto. Nos parece que la campaña ha servido para movilizar a una parte del electorado que no había participado en anteriores convocatorias electorales. Pero la influencia en el resultado no ha sido tan decisiva, puesto que, como puede comprobarse, se mantiene la tendencia de las últimas convocatorias. Con relación a las autonómicas de 1998 -las generales no sirven como punto de referencia, por la ausencia de $\mathrm{EH}-\mathrm{los}$ nacionalistas descienden casi un dos por ciento en sus apoyos (del 54,6 al 52,8$)$, mientras que los no nacionalistas suben ese mismo porcentaje (del 44,6 al 46,6 ). En cuanto a número de escaños, el nacionalismo pierde uno, en beneficio de IU, que, en este caso, puede considerarse más cercano al bando nacionalista que al no nacionalista.

Fue un mensaje común a todos los partidos la llamada a la participación electoral suponiendo que un incremento del número de votantes redundaría en beneficio propio. Una vez conocidos los resultados podría pensarse, como así ha sido en muchos casos, que fueron los nacionalistas quienes acertaron al sentirse presumiblemente beneficiados por el aumento de la participación y que los constitucionalistas erraron en el intento. Pues bien, esto no es exactamente así. Resulta innegable que la coalición PNV-EA aglutinó muchos votos nuevos. Sin embargo, no menos cierto es que, si el PP y el PSE habian obtenido 589.818 votos en las generales de 2000 , debían mantener a toda costa esta cifra, sabiendo,como sabían, que algunos de estos votos de las generales eran "voto útil" prestado del PNV en las autonómicas. Así pues, los constitucionalistas tampoco se equivocaron al aspirar a un aumento de la participación porque, ante una movilización nacionalista de tanta importancia, si no hubieran empujado a las urnas a todos sus votantes e incluso aquellos votos propios que habían mostrado una actitud más pasiva en otras convocatorias, los resultados hubieran sido peores, sin duda.

No es acertado, ni siquiera lógico, pensar que el PP no se llevó ningún voto de ese porcentaje de aumento de la participación,que, como veremos fue de casi un $15 \%$. Porque el PNV no sólo se nutrió de los votos de nuevos electores $y$ de antiguos abstencionistas, principal-

13 Llera Ramo, F.J., “Cambio político en Euskadi: Entre Lizarra y AjuriaEnea», op. cit., p. 56. 
mente de la mitad de los votos de EH que no habían acudido a las urnas por la llamada expresa en ese sentido que realizó la formación radical en las elecciones generales de 2000 . Se nutrió también de votos uprestados" al PP y al PSOE en estas mismas elecciones generales, tan polarizadas entre los dos principales partidos a nivel nacional. Se alimentó, por último, de una bolsa de votos en blanco y votos nulos que, al igual que ocurrió con la abstención, se redujeron en un porcentaje muy elevado en las autonómicas de 2001.

Lo que sí ofrece mayor credibilidad es pensar que el electorado de los partidos no nacionalistas ya estaba movilizado antes del inicio oficial de la campaña. En cambio, el esfuerzo que realizaron los nacionalistas a partir del 26 de abril provocó una movilización de su electorado, que de alguna manera equilibró la de los partidos constitucionalistas. Quizá contribuyó también al incremento de la participación nacionalista una cierta radicalización del mensaje del PP y el PSE en el período oficial de campaña.

\subsection{Diversidad de encuestas y dudosa credibilidad.}

Los meses previos a la cita electoral se hicieron públicas numerosas encuestas, en las que venía a reflejarse una conclusión parecida: los dos bloques (PNV-EA por un lado, PP-PSE por otro) tenían posibilidades muy similares de gobernar. EI PP y el PSE sólo podrian hacerlo si obtenían la mayoría absoluta o se quedaban cerca, lo cual parecía factible, pero de modo muy ajustado. El PNV podía mantener su posición como primera fuerza política gracias a su pacto con EA, y, en caso de que los no nacionalistas se quedasen lejos de la mayoría absoluta, podría gobernar de nuevo en minoría, o con apoyos puntuales de IU-EB o incluso de EH. Esta última posibilidad fue rotundamente rechazada en los últimos días de campaña por el lehendakari.

El interés de estas elecciones desbordaba, de nuevo, las fronteras del País Vasco, y en el resto de España las miradas estaban pendientes de lo que pudiese ocurrir. Esto tuvo su reflejo en los medios de comunicación que, de igual modo que en 1998, encargaron y publicaron una buena cantidad de sondeos preelectorales. Tele 5 volvió a poner en marcha, como en las anteriores elecciones vascas, un barómetro diario durante la campaña. La sensación, como hemos dicho, era que el resultado final se iba a dirimir por muy pocos votos, puesto que parecía que las posiciones se mantenían estables. La incógnita volvía a residir en la orientación que pudiese 
tener el voto oculto. Las empresas demoscópicas confesaban que, para obtener una respuesta que sirviese para ser contabilizada, debían abordar a tres o cuatro ciudadanos vascos. El reto para ellas estaba en saber detectar cuál sería la tendencia de este voto el día de las elecciones. Siguiendo criterios de anteriores ocasiones, lo probable era que el PP obtuviese algún apoyo más de los manifestados, y los nacionalistas algunos menos.

\begin{tabular}{|c|c|c|c|c|c|c|c|c|c|}
\hline 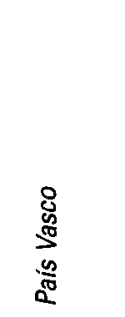 & 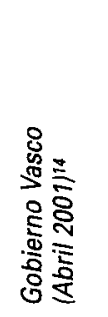 & $\begin{array}{l}\frac{2}{5} \\
\stackrel{2}{0} \\
\bar{\Sigma} \\
\frac{1}{0} \\
0 \\
0\end{array}$ & 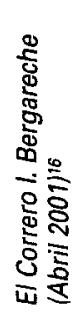 & 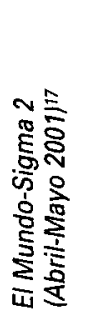 & 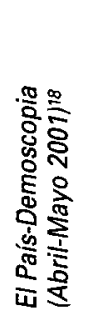 & 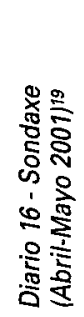 & 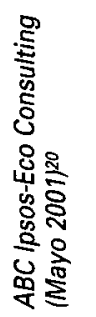 & 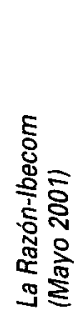 & 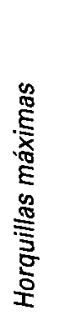 \\
\hline PNV-EA & $27-29$ & 28-31 & 28 & $27-30$ & 30 & 30 & $25-28$ & 24 & 24-31 \\
\hline PP - UA & $19-20$ & $21-23$ & 20 & $20-23$ & $21-22$ & 19 & $20-22$ & 22 & $19-23$ \\
\hline PSE-EE & $14-16$ & 14-16 & 14 & 14-16 & 15 & 14 & 14-15 & 15 & $14-16$ \\
\hline EH & 9-10 & $8-9$ & 10 & $7-8$ & $7-8$ & 9 & $10-11$ & 11 & $7-11$ \\
\hline IU - EB & 3 & $1-2$ & 3 & $2-3$ & $1-2$ & 3 & $2-3$ & 3 & $1-3$ \\
\hline OTROS & - & - & - & - & - & - & - & - & - \\
\hline
\end{tabular}

\section{FICHA TÉCNICA:}

- Recogida de datos: Entrevista individual a domicilio con cuestionario estructurado y cerrado.

- Análisis de resultados: Gabinete de Prospección Sociológica del Gobierno Vasco.

- Muestra de población: 2.996 entrevistas a mayores de 18 años. 644 en Alava, 1.330 en Bizkaia y 1.022 en Gipuzkoa.

- Selección: Procedimiento polietápico y estratificado con 144 puntos de muestreo de 14 encuestas.

- Error muestral: $\pm 3,9 \%$ para Alava, $\pm 2,7 \%$ para Bizkaia, $y \pm 3,1 \%$ para Gipuzkoa. Nivel de confianza de $95,5 \%$ siendo $p=q=0,5$.

\section{FICHA TECNICA:}

- Ambito: Comunidad Autónoma del País Vasco.

- Universo: Población de ambos sexos de 18 años y más.

- Tamaño de la muestra:

Diseñada: 2.500 entrevistas, con la siguiente distribución provincial: Alava 695 , Guipuzcoa 826, Vizcaya 979.

Realizada: 2.487 entrevistas, con la siguiente distribución provincial: Alava 695 , Guipuzcoa 813 y Vizcaya 979.

- Afiliación: No proporcional.

- Ponderación: Para tratar la muestra para el conjunto de la comunidad autónoma es necesaria la aplicación de los siguientes coeficientes de ponderación: Alava 0,471 ; Guipuzcoa 0,990 y Vizcaya 1,384 . 
- Puntos de Muestreo: 76 municipios y 3 provincias.

- Procedimiento de muestreo: Polietápico, estratificado por conglomerados, con selección de las unidades primarias de muestreo (municipios) y de las unidades secundarias (secciones) de forma aleatoria proporcional, y de las unidades últimas (individuos) por rutas aleatorias y cuotas de sexo y edad. Los estratos se han formado según el tamaño de hábitat de los municipios, dividido en 6 categorías: menor o igual a 2.000 habitantes; de 2.001 a 10.000 ; de 10.001 a 50.000 ; de 50.001 a 100.000; de 100.001 a 400.000 , y más de 400.000 habitantes. Los cuestionarios se han aplicado mediante entrevista personal en los domicilios.

- Error muestral. Para un nivel de confianza del $95,5 \%$ (dos sigmas) y $p=q$, el error es de $\pm 2,0 \%$ para el conjunto de la muestra y en el supuesto de muestreo aleatorio simple. Para cada una de las provincias los errores son: Alava $\pm 3,79 \%$, Guipuzcoa $\pm 3,51 \%$, y Vizcaya $\pm 3,20 \%$.

- Fecha de realización: Del 17 al 25 de abril de 2001.

16 FICHA TÉCNICA:

- Universo de referencia: La población vasca con derecho a voto (mayor de 18 años)

- Tamaño de la muestra: 3.600 entrevistas personales con cuestionario escrito. 1.200 en Alava, 1.200 en Gipuzkoa y 1.200 en Vizcaya.

- Fecha de recogida de la información: Del 26 al 29 de Abril de 2001.

- Ambito: La Comunidad Autónoma Vasca con 27 puntos de muestreo.

- Criterio de selección de la muestra: Proporcional para los cortes de edad y sexo. Por cuotas de voto dado en las elecciones autonómicas de octubre de 1998.

- Margen de error: En el caso menos favorable en que $\mathrm{p}=\mathrm{q}=\mathbf{5 0} \%$, con una fiabilidad del $95,5 \%$, para los datos globales: $\pm 1,8 \%$; y para cada una de las provincias: $\pm 2,9 \%$.

- Responsable de campo: Maite Molinos

- Dirección: Isabel Bergareche.

17 FICHA TÉCNICA:

- Universo: Mayores de 18 años.

- Ambito: País Vasco

- Muestra: 1.400 entrevistas con un error posible de $\pm 2,67 \%$ para un nivel de confianza del $95,5 \%$ y un $p=q=50$.

- Selección: Polietápica, estrtificada, aleatoria.

- Entrevista: Telefónica.

- Fecha: Del 27 de Abril al 3 de Mayo de 2001.

- Realización: SIGMA DOS. Ns/Nc en voto declarado es del $27,2 \%$ 18 FICHA TÉCNICA:

- Ambito: Comunidad autónoma vasca.

- Universo: Individuos de 18 años en adelante residentes en hogares del ámbito señalado y censados en la CAV.

- Tamaño y distribución de la muestra: 1.814 entrevistas en 125 municipios.

- Método de recogida de información: Cuestionario administrado a través de entrevista telefónica asistida por ordenador. La realización de las 1.814 entrevistas válidas ha conllevado 6.144 rechazos.

- Error de muestreo: Total País Vasco $\pm 3,1 \%$; cada provincia, $4,1 \%$.

- Fechas de trabajo de campo: Entre el 25 de abril y el 3 de mayo.

- Tratamiento de la información: DEMOSCOPIA, S.A.

19 FICHA TÉCNICA:

- Encuesta realizada por Sondaxe en el territorio administrativo del País Vasco.

- Universo: Población residente con 18 o más edad. 
Como puede apreciarse, la relación de fuerzas entre nacionalistas y no nacionalistas se mantenía bastante equilibrada. La suma de escaños nacionalistas podía oscilar entre los 31 y los 42 . La de los no nacionalistas oscilaría entre los 33 y los 39, dejando al margen a IU-EB, por su postura de equidistancia. Lo único que parecía claro es el trasvase de voto desde EH hacia el PNV-EA.

No obstante, llamaba la atención la diferencia de adjudicación de escaños entre algunas encuestas. Por ejemplo, era llamativo el bajo número de escaños que $A B C$ y La Razón adjudicaban al PNV, en comparación con los demás medios. Esto indicaba que la elaboración final de los resultados de las encuestas había seguido criterios muy diferentes en unos medios y en otros. Puede ser también interesante ver los resultados desglosados por Territorios Históricos.

\begin{tabular}{|c|c|c|c|c|c|c|c|c|}
\hline 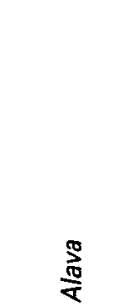 & 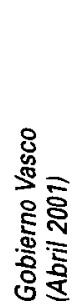 & 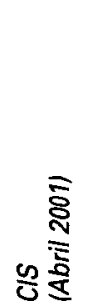 & 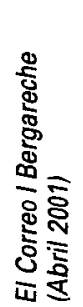 & 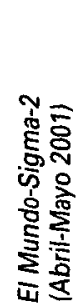 & 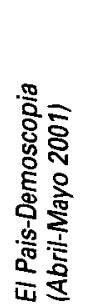 & 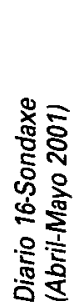 & 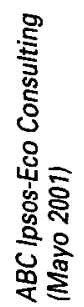 & 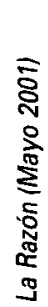 \\
\hline PNV-EA & $7-8$ & $7-8$ & 8 & $8-9$ & 8 & 8 & $7-8$ & 6 \\
\hline$\overline{P P}$ - UA & 9 & $10-11$ & 9 & $9-10$ & $10-11$ & 9 & $9-10$ & 11 \\
\hline PSE-EE & $5-6$ & $5-6$ & 5 & $5-6$ & 5 & 5 & $5-6$ & 5 \\
\hline EH & 2 & 2 & 2 & 1 & $1-2$ & 2 & 2 & 2 \\
\hline IU - EB & 1 & $0-1$ & 1 & $0-1$ & $0-1$ & 1 & 1 & 1 \\
\hline OTROS & - & - & - & - & - & - & - & - \\
\hline
\end{tabular}

- Tamaño de la muestra: 1.800 entrevistas, 600 por circunscripción

- Fecha: 25, 26, 27, 28 y 30 de Abril y 2 y 3 de Mayo de 2001.

20 FICHA TÉCNICA:

- Universo: Población de 18 y más años, residente en el País Vasco.

- Muestra: 900 entrevistas para el total del País Vasco con asignación de 300 entrevistas en cada circunscripción. Muestras representativas por tamaños de municipios en cada provincia con selección de la última unidad muestral por cuotas de sexo y edad. En el caso de una muestra probabilística, el margen de error sería de $\pm 3,3 \%$ para el total País Vasco $(p=q=50 \%$ y margen de confianza del $95,5 \%)$

- Metodología: Entrevistas telefónicas mediante sistema CATI.

- Trabajo de campo: Las entrevistas se han realizado entre los días 2 y 3 de mayo de 2001.

- Dirección técnica: Ipsos-Eco Consulting. 
Si tenemos en cuenta que la suma de escaños del PP con UA era de 9, podemos observar cómo la coalición de ambos partidos no aportaba nuevos votos a los que obtenían por separado. Al menos, varias de las encuestas así lo indicaban. Alguna le daba un crecimiento de uno o incluso dos escaños, pero muchas mantenian en 9 el número total. Aparentemente Izquierda Unida podía jugarse aquí alcanzar o no un escaño. El resto de los resultados seguía las tendencias generales.

\begin{tabular}{|c|c|c|c|c|c|c|c|c|}
\hline 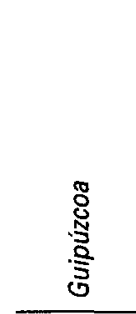 & 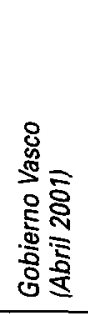 & 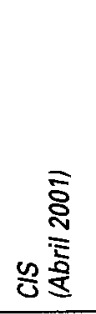 & 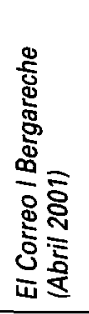 & 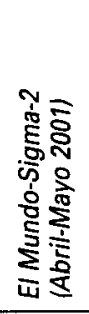 & 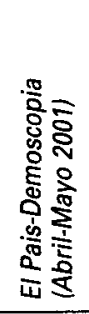 & 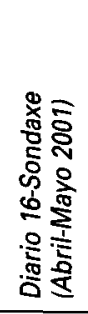 & 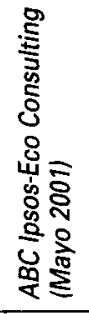 & 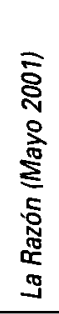 \\
\hline PNV-EA & 10 & $11-12$ & 10 & $9-10$ & 11 & 11 & $9-10$ & 8 \\
\hline$\overline{P P}$ - UA & $4-5$ & $5-6$ & 5 & $5-6$ & 5 & 5 & 5 & 5 \\
\hline PSE-EE & 4-5 & $4-5$ & 4 & $4-5$ & 5 & 4 & $4-5$ & 5 \\
\hline EH & 5 & 4 & 5 & $4-5$ & 4 & 4 & $5-6$ & 6 \\
\hline IU - EB & 1 & 0 & 1 & 1 & 0 & 1 & $0-1$ & 1 \\
\hline OTROS & - & - & - & - & - & - & - & - \\
\hline
\end{tabular}

La coalición PNV-EA se situaría claramente como primera fuerza en Guipúzcoa, lo cual tenía su lógica si tenemos en cuenta los apoyos que habían logrado por separado. Además, recibían aquí también buena parte de los votos de EH. Izquierda Unida podría obtener un escaño, pero estaba en el límite. En cuanto al PP y PSE mantenían sus resultados, y se veía que les costaba mucho subir en esta provincia: debían ir arañando escaño a escaño. 


\begin{tabular}{|c|c|c|c|c|c|c|c|c|}
\hline 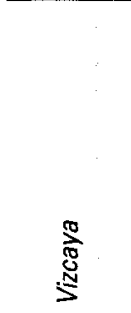 & 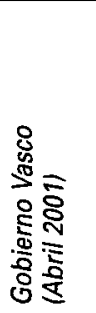 & 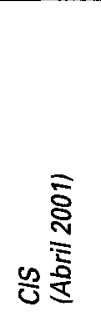 & 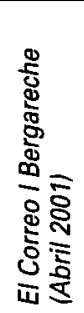 & 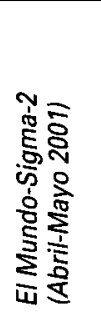 & 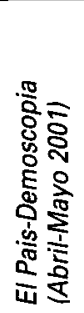 & 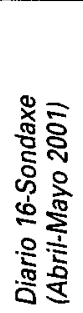 & 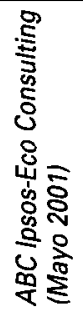 & 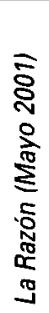 \\
\hline PNV-EA & $10-11$ & $10-11$ & 10 & $10-11$ & 11 & 11 & 9-10 & 10 \\
\hline PP - UA & 6 & 6 & 6 & $6-7$ & 6 & 5 & $6-7$ & 6 \\
\hline PSE-EE & 5 & 4-5 & 5 & 5 & 5 & 5 & 5 & 5 \\
\hline EH & $2-3$ & $2-3$ & 3 & 2 & 2 & 3 & 3 & 3 \\
\hline IU - EB & 1 & 1 & 1 & 1 & 1 & 1 & 1 & 1 \\
\hline OTROS & - & - & - & - & - & - & - & - \\
\hline
\end{tabular}

Vizcaya era el único territorio en el que IU parecía tener asegurado un escaño. Se producía aquí también un trasvase de EH hacia el PNV, y parecía que PP y PSE alcanzarían 6 y 5 escaños, respectivamente.

Especialmente polémica fue la última encuesta del CIS, que no fue preparada a tiempo para ser publicada en los medios, aparentemente por problemas técnicos. Los partidos de la oposición al PP criticaron duramente esta ineficacia, $y$ la interpretaron como un intento de ocultar resultados que no debían ser muy favorables a los intereses del partido en el gobierno de España. Izquierda Unida, que tuvo acceso a los datos, como los demás partidos, el lunes previo a las elecciones, convocó una rueda de prensa en la que comunicó a los informadores los resultados de la encuesta, que aparecieron en todos los medios de comunicación nacionales el martes, día en el cual, según la ley, ya no podían hacerse públicos.

Los sondeos reflejaban, en todo caso, que la movilización del electorado iba a ser superior a la de otras convocatorias. Si la tendencia de los partidos no nacionalistas fue ascendente en los meses previos a la campaña electoral, durante los úitimos quince días pareció estancarse el apoyo a estas fuerzas políticas, mientras que se percibía, cada vez de modo más claro, que un buen número de votantes de $\mathrm{EH}$ iba a respaldar en esta ocasión la coalición nacionalista moderada. Con los terroristas en acción, los votos que EH habia recuperado en 1998 podían huir de nuevo hacia posiciones más moderadas. 
De modo que el PNV aparecía en los últimos días con una leve tendencia al alza, mientras que PP y PSOE se estancaban. Sin embargo, como en ocasiones anteriores, el problema residía en valorar correctamente el significado del voto oculto. Mientras que los partidos no nacionalistas pensaban que la mayoría de este voto era suya, los nacionalistas no lo tenían tan claro. En todo caso, la participación se iba a incrementar, como estaba poniendo de relieve el ritmo de recepción de votos por correo, que casi triplicaba al de convocatorias anteriores.

Las encuestas mostraban, por otra parte, una gran división entre el estado de opinión en la sociedad vasca y en el resto de España. La prueba más clara era, quizá, que mientras Mayor Oreja era el candidato más valorado a nivel nacional, en el País Vasco estaba incluso por detrás de Arnaldo Otegui, es decir, era el último en índice de valoración de candidatos. Este dato fue comentado por los analistas en los meses previos a la convocatoria electoral21, pero siempre quedaba la duda de si era un dato sincero, o se debía, una vez más, al grado de ocultación de los apoyos al PP que se detectaba en las encuestas. Como en 1998, no sólo había muchos indecisos, sino que también muchos ciudadanos vascos no querían desvelar su opinión al ser preguntados. Si en 1998, con tregua, era significativa esta actitud, que reflejaba sin duda la presión con que se vivía esta campaña, a pesar de que los terroristas no estuviesen actuando ${ }^{22}$, ahora tenía todavía mayor explicación, en las nuevas circunstancias de tensión callejera y de actividad terrorista.

21 «¿Cómo es posible que el político mejor valorado en España sea el peor valorado en el País Vasco? ¿Cómo es posible que su valoración sea inferior a la de un político como Arnaldo Otegi que, en el momento de hacerse la encuesta, había justificado nada menos que veintisiete asesinatos de ETA? ¿Será indicio dicho dato de que en la opinión pública del País Vasco existe una irritación respecto del PP simétrica a la que existe respecto de ETA?" Cfr. Pérez RoYo, J., "¿Irritación simétrica?", en El País, viernes, 23 de marzo de 2001.

22 A la pregunta "¿Qué partido cree que va a ganar estas elecciones?", de la encuesta realizada por Gallup, un $16,5 \%$ No sabe/No contesta. (Cfr. $A B C 18$ de octubre de 1998, p. 35.). Más significativa todavía es la ausencia de respuesta a la pregunta "¿Qué partido le gustaría que ganara?», de la encuesta de Demoscopia para El País: el No sabe/No contesta alcanza el $30 \%$, el mismo porcentaje de los que muestran sus preferencias por una victoria del PNV (Cfr. El País 18 de octubre de 1998, p. 18). 


\section{LAS ELECCIONES DEL 13 DE MAYO.}

\subsection{Resultados globales.}

El número de electores convocados a las urnas era algo menor que en 1998, en concreto 1.813.356, de los cuales ejercieron su derecho al voto un $78,97 \%$ del total. La cifra es la más alta de todas las elecciones autonómicas, y la segunda en toda la reciente historia democrática en Euskadi, sólo por detrás de las elecciones generales de 1982. Ya el número de votos por correo y las cifras de participación que iban llegando durante el día anunciaban una gran movilización: quedaba por ver si esto suponía un cambio en la correlación de fuerzas en el Parlamento. En la siguiente tabla podemos observar los diferentes porcentajes de participación que ha habido hasta ahora en el País Vasco ${ }^{23}$.

Evolución de la participación

\begin{tabular}{lcc}
\hline & Autonómicas & Generales \\
\hline 1977 & & 76,9 \\
\hline 1979 & & 65,9 \\
\hline 1980 & 59,76 & \\
\hline 1982 & & 79,37 \\
\hline 1984 & 68,49 & \\
\hline 1986 & 69,62 & 67,58 \\
\hline 1989 & & 66,89 \\
\hline 1990 & 60,99 & \\
\hline 1993 & & 69,63 \\
\hline 1994 & 59,69 & \\
\hline 1996 & & 71,53 \\
\hline 1998 & 70,7 & \\
\hline 2000 & & 63,84 \\
\hline 2001 & 78,97 & \\
\hline
\end{tabular}

El elevado número de votantes motivó una positiva reacción de todos los partidos en sus primeras declaraciones, en las que los líderes

23 Salvo que indiquemos lo contrario, todos los datos que figuran en este trabajo se obtienen de la fuente del Departamento del Interior el Gobierno Vasco, Dirección de Procesos electorales y documentación, y pueden consultarse en la siguiente dirección de Internet: www.euskadi.net. 
políticos se felicitaban de la elevada participación, muestra del interés de los vascos en estas elecciones. Además, en todo caso, se incrementaba la legitimidad democrática del resultado.

Como puede apreciarse, la tendencia siempre ha sido la de alcanzar una mayor participación en las elecciones generales que en las autonómicas, con la excepción de 1986. Pero, desde 1998, cuando casi se llegó al mismo nivel de participación que en las generales de 1996 esta tendencia ha cambiado. Ahora se ha visto de nuevo confirmado, si comparamos el resultado de las autonómicas con las generales de 2000. El incremento de participación se percibe también en las generales, aunque se nota más en las autonómicas, porque se parte de niveles más bajos de votación en convocatorias anteriores. Se ha dicho incluso que, de no haber sido por la llamada a la abstención de $E H$, en las últimas generales se habría incrementado la participación en Euskadi, al contrario que en el resto de España ${ }^{24}$.

La explicación que se daba a la mayor participación de los electores en las generales era que existía un grupo de votantes de partidos no nacionalistas que se abstenían en las autonómicas, por no verse tan motivados a acudir a las urnas como en las elecciones de ámbito nacional. Pero la ausencia de diferencias en el nivel de participación a partir de 1998 es un dato que quizá no se valoró adecuadamente en su momento por parte de los partidos no nacionalistas, que seguían pensando que podían ganar votos procedentes de las bolsas de abstencionistas.

En la tabla que se muestra a continuación se recogen los resultados de los principales partidos políticos. Se incluyen también los datos comparativos de las dos últimas elecciones autonómicas.

\begin{tabular}{|c|c|c|c|c|c|c|c|c|c|}
\hline 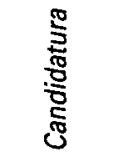 & 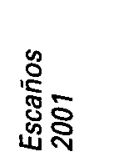 & ః̊:๊ & $\begin{array}{l}\bar{S} \\
\text { D } \\
20\end{array}$ & 今ّ̊: & $\begin{array}{l}\frac{2}{2} \\
\frac{2}{20}\end{array}$ & 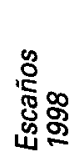 & 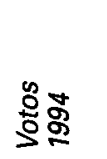 & 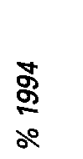 & 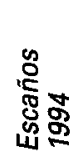 \\
\hline EAJ-PNV & $33(+\mathrm{EA})$ & 604.222 & 42,72 & 350.322 & 28,01 & 21 & 304.346 & 29,84 & 22 \\
\hline PSE-EE & 13 & 253.195 & 17,90 & 220.052 & 17,60 & 14 & 174.682 & 17,13 & 12 \\
\hline $\mathrm{PP}$ & $19(+\cup A)$ & 326.933 & 23,12 & 251.743 & 20,13 & 16 & 146.960 & 14,41 & 11 \\
\hline EA & - & - & - & 108.635 & 8,69 & 6 & 105.136 & 10,31 & 8 \\
\hline $\mathrm{HB} / \mathrm{EH}$ & 7 & 143.139 & 10,12 & 224.001 & 17,91 & 14 & 166.147 & 16,29 & 11 \\
\hline IU/EB & 3 & 78.862 & 5,58 & 71.064 & 5,68 & 2 & 93.291 & 9,15 & 6 \\
\hline UA & - & - & - & 15.738 & 1,26 & 2 & 27.797 & 2,73 & 5 \\
\hline
\end{tabular}

24 WeRT, J.l., «País Vasco: Otro punto de vista. Lo que aún no se ha dicho», op. cit., p. 7. 
A la vista de estos datos, podemos obtener ya algunas conclusiones, aunque convendrá desglosar los votos por provincias para poder establecer una valoración más precisa. No obstante, es clara la victoria de la coalición PNV-EA, que incrementa el número de escaños en 6 , si tenemos en cuenta que entre los dos sumaban por separado 27 escaños en 1998. Además, la suma de votos de PNV y EA también es superior a lo que obtuvieron en 1998: 604.222 frente a 458.957. La mayor parte de esos votos procede, sin duda, de los que pierde $\mathrm{EH}$, pero muchos también llegan desde la abstención o son nuevos votantes.

El descenso de EH es espectacular, pues pierde la mitad de los escaños que tenía y casi la mitad de sus votos. Se sitúa en niveles mínimos históricos. Parece, a primera vista, que los 7 escaños de EH van a parar al PNV-EA(6) y a IU (1), a quien su estrategia de equidistancia entre los polos teóricamente radicales y la firma del Pacto de Estella le dan sus frutos.

Antes de valorar los datos del PP y el PSOE nos parece conveniente introducir otro elemento comparativo: las elecciones generales de 2000 y las europeas de 1999. Si los partidos nacionales tenían como reto mantener el nivel de votación de unas generales, veamos si lo consiguen.

\begin{tabular}{|c|c|c|c|c|c|c|c|c|}
\hline 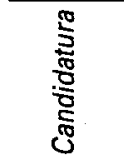 & 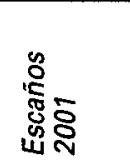 & కొర్వ & $\begin{array}{l}\overline{8} \\
\text { ন } \\
\text { வீ }\end{array}$ & 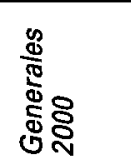 & $\begin{array}{l}8 \\
\text { ঠ } \\
\text { ㅇ }\end{array}$ & 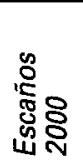 & 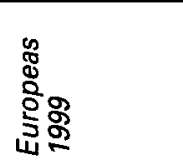 & 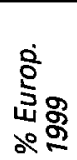 \\
\hline EAJ-PNV & $33(+\mathrm{EA})$ & 604.222 & 42,72 & 347.417 & 31,32 & 7 & $392.800(+E A)$ & 34,53 \\
\hline PSE-EE & 13 & 253.195 & 17,90 & 266.583 & 24,03 & 4 & 226.187 & 19,88 \\
\hline $\mathrm{PP}$ & $19(+U A)$ & 326.933 & 23,12 & 323.235 & 29,14 & 7 & 228.688 & 20,10 \\
\hline$\overline{E A}$ & - & - & - & 86.557 & 7,80 & 6 & - & - \\
\hline $\mathrm{HB} / \mathrm{EH}$ & 7 & 143.139 & 10,12 & - & - & - & 225.796 & 19,85 \\
\hline IU/EB & 3 & 78.862 & 5,58 & 62.293 & 5,62 & - & 45.617 & 4,01 \\
\hline UA & - & - & & - & - & - & - & \\
\hline
\end{tabular}

Como puede apreciarse, el PP incrementa algo su nivel máximo de votación, que había sido el de las generales de 2000 , pero en condiciones muy distintas. Al haber subido considerablemente el grado de participación, esta diferencia positiva en términos absolutos no es tal en términos relativos. El porcentaje de apoyo a los populares desciende seis puntos en Euskadi con relación a las generales de 2000. 
Por otro lado, el Partido Popular desciende incluso en números absolutos en Álava, donde iba en coalición con Unidad Alavesa. La mejoría se produce en los otros dos Territorios Históricos, de modo que se consolida como segunda fuerza política del País Vasco, sin alcanzar las expectativas más optimistas de algunas encuestas.

EI PSE-EE no logra mantener su apoyo electoral de las generales de 2000 en números absolutos, y el descenso es mayor en porcentaje: casi siete puntos. Como detalle interesante, pierde por sólo un puñado de votos un escaño en Vizcaya. Sin embargo, como consecuencia de la debacle de $\mathrm{EH}$, recupera la posición de tercera fuerza en el Pais Vasco.

Si comparamos los resultados con los de las dos últimas elecciones autonómicas, el análisis es diferente: el PP sube de modo considerable su nivel de apoyos, pasando del $14,4 \%$ en 1994 al $23,12 \%$ en 2001. EI PSOE se mantiene por encima del $17 \%$, incrementando también siempre su nivel de votos y porcentaje. Lo que ocurre es que ambos partidos se habían planteado estas elecciones con unas expectativas mucho mayores. La movilización del electorado nacionalista (una parte, el de EH, no había votado en las generales) provoca que, a pesar de mantener sustancialmente sus electores, el nivel de respaldo en términos relativos no sea suficiente para articular una alternativa alrededor de los dos partidos no nacionalistas.

El gran perdedor de las elecciones es Euskal Herritarrok. Como se preveía, acusa el desgaste de la actividad terrorista de ETA, pero de un modo mucho más acentuado que el anunciado por las encuestas. Además, como se ha puesto de relieve en las encuestas, el electorado de EH temía más la derrota del PNV que el propio electorado del PNV25. Este descenso fue gratamente recibido por la sociedad vasca, y por la española, que quizá percibió este dato como el más positivo de las elecciones. En general, en el resto de España la reacción fue de disgusto ante el resultado, puesto que la gran campaña mediática del gobierno de Madrid había hecho creer a los españoles en la posibilidad de una victoria de la coalición PP-PSE.

Ya hemos anticipado que IU mejora sus resultados, y además supera el $5 \%$ en los tres Territorios Históricos, por lo cual no habría

25 Encuesta de Demoscopia en El País, 7 de mayo de 2001. Lo comenta Patxo Unzueta en su artículo "Las razones de los perdedores", en El País, 24 de mayo de 2001. 
hecho falta la modificación legislativa que habia reducido la barrera electoral del 5 al $3 \%$, como pago del PNV a IU por el apoyo prestado desde la firma del Pacto de Estella. No obstante, IU no llega a recuperar los niveles de representación y apoyo que logró en 1994, con 6 escaños, 93.291 sufragios, que representaban un $9,15 \%$ de los votantes.

Una referencia que puede ayudarnos a situar en su justo término el apoyo de cada uno de los partidos es la de su porcentaje de apoyo no con respecto a los votantes, sino con relación al censo. Según este cálculo, los nacionalistas no alcanzan, ni mucho menos, su mayor cuota de apoyo electoral sobre el censo, que habían logrado en 1986, con una participación mucho menor. Sin embargo, los no nacionalistas consiguen el mejor resultado de su historia, teniendo en cuenta los datos sólo de las autonómicas. Lo que ocurre en el bando nacionalista es que la concentración de voto es tan grande en la coalición PNV-EA que estos dos partidos sí consiguen su mayor porcentaje de apoyo histórico sobre el censo. También lo logra el PP, puesto que consigue el mejor resultado obtenido por un partido no nacionalista en elecciones autonómicas vascas (un $18,1 \%$ sobre el censo), más incluso que el que había alcanzado el PSE en 1986 (un 15,2\%) ${ }^{26}$.

Veamos a continuación los resultados en cada Territorio Histórico, porque de esta manera se puede analizar mejor el trasvase de votos entre unas fuerzas y otras.

\subsection{Resultados por Territorios Históricos.}

\begin{tabular}{lrrrrrr}
\hline Álava & Votos 2001(\%) & Votos $1998(\%)$ & $\% 1994$ & $\begin{array}{c}\text { Esc. } \\
2001\end{array}$ & $\begin{array}{c}\text { Esc. } \\
98\end{array}$ & $\begin{array}{c}\text { Esc. } \\
94\end{array}$ \\
\hline EAJ-PNV & $64.832(33,85)$ & $36.830(21,95)$ & 22,11 & 9 & 6 & 6 \\
\hline PSE-EE & $39.469(20,61)$ & $28.574(17,03)$ & 15,84 & 5 & 5 & 4 \\
\hline PP & $62.737(32,75)$ & $45.273(26,98)$ & 16,18 & 9 & 7 & 4 \\
\hline EA & - & $10.700(6,38)$ & 7,36 & - & 1 & 2 \\
\hline HB/EH & $11.836(6,18)$ & $20.536(12,24)$ & 10,25 & 1 & 3 & 2 \\
\hline IU/EB & $11.430(5,97)$ & $9.625(5,74)$ & 9,23 & 1 & 1 & 2 \\
\hline UA & - & $14.278(8,51)$ & 18,83 & - & 2 & 5 \\
\hline
\end{tabular}
op. cit., p. 9.

26 WERT, J.I., "País Vasco: Otro punto de vista. Lo que aún no se ha dicho", 


\begin{tabular}{lcrrrrr}
\hline Vizcaya & Votos 2001 (\%) & Votos 1998 & \% 1994 & $\begin{array}{r}\text { Esc. } \\
2001\end{array}$ & $\begin{array}{r}\text { Esc. } \\
98\end{array}$ & $\begin{array}{r}\text { Esc. } \\
94\end{array}$ \\
\hline EAJ-PNV & $335.945(43,77)$ & $222.902(32,99)$ & 35,66 & 12 & 9 & 10 \\
\hline PSE-EE & $139.684(18,20)$ & $125.022(18,50)$ & 17,66 & 4 & 5 & 4 \\
\hline PP & $181.404(23,64)$ & $138.642(20,52)$ & 15,27 & 6 & 5 & 4 \\
\hline EA & - & $41.011(6,07)$ & 7,20 & - & 1 & 2 \\
\hline HB/EH & $61.894(8,06)$ & $99.936(14,79)$ & 13,60 & 2 & 4 & 3 \\
\hline IU/EB & $43.701(5,69)$ & $42.576(6,30)$ & 10,21 & 1 & 1 & 2 \\
\hline Guipúzcoa & Votos $2001(\%)$ & Votos 1998 & $\% 1994$ & Esc. & Esc. & Esc. \\
\hline EAJ-PNV & $203.445(44,69)$ & $88.226(22,02)$ & 22,79 & 12 & 6 & 6 \\
\hline PSE-EE & $74.042(16,26)$ & $65.011(16,22)$ & 16,74 & 4 & 4 & 4 \\
\hline PP & $82.792(18,19)$ & $66.665(16,64)$ & 12,14 & 4 & 4 & 3 \\
\hline EA & & $56.589(14,12)$ & 17,08 & - & 4 & 4 \\
\hline HB/EH & $69.409(15,25)$ & $102.792(25,65)$ & 23,63 & 4 & 7 & 6 \\
\hline IU/EB & $23.731(5,21)$ & $18.634(4,65)$ & 7,23 & 1 & 0 & 2 \\
\hline
\end{tabular}

Aparte del caso alavés, que estudiamos en mayor profundidad en otro lugar de este trabajo, y en donde no funciona la coalición PP-UA, podemos observar cómo el trasvase de voto desde EH al PNV es mucho mayor que el que predecían las encuestas, aunque el incremento de voto nacionalista procede también de antiguos abstencionistas, electores que en las generales habían votado PP o PSE, y además de nuevos votantes.

EL PP y el PSE suben en todos los territorios. Incluso la coalición PP-UA en Álava supera la suma del PP más UA en 1998, pero el problema para estos partidos es que intentaron en todo momento una comparación con los resultados que habían obtenido en las generales, y por ello la sensación era de derrota, cuando en realidad habían mejorado los resultados en las tres provincias.

Además, en Vizcaya el PSOE pierde el quinto escaño en beneficio del PNV sólo por 300 votos. El resto con el que el PNV logra su escaño número 12 es de 27.995,4 votos, mientras que el quinto del PSOE le habría costado $27.936,8$. Una diferencia de 60 votos que, multiplicada por 5, habrían hecho necesarios 300 sufragios más para el PSE.

Por otro lado, al PP le faltan en Guipúzcoa 1.975 votos para arrebatarle un escaño al PNV, el que haría el número 12 para los nacionalistas y el número 5 para los populares (el escaño 12 le cuesta al PNV $16.953,7$ votos, y el quinto le habría costado al PP 16.558,4). Como puede verse, por escasa diferencia de votos podía haberse dado un 
baile de un escaño tanto en Vizcaya como en Guipúzcoa, que podría haber cambiado la situación final, si en Álava hubiese dado mejores resultados la coalición PP-UA.

En definitiva, la elevada participación -como ya había ocurrido en 1998- no se traduce, sin embargo, en un cambio sustancial en el mapa político vasco. Al contrario, la tendencia es prácticamente la misma. Descienden en uno los escaños ocupados por fuerzas nacionalistas (40) y suben uno los no nacionalistas (34), pero teniendo en cuenta que, entre estos últimos, está IU, que probablemente recibió alguno de los votos de EH, y que no es posible clasificar de un modo claro. No obstante, en número de votos totales sí se observa una tendencia al alza mayor entre los partidos no nacionalistas que en los otros, lo cual es una constante en las últimas elecciones autonómicas. En la tabla siguiente se puede comprobar este dato: la diferencia entre unos y otros es cada vez menor. Hacemos notar, además, cómo en las elecciones de 1986 los nacionalistas consiguen más votos que en estas últimas, con un censo electoral que reunía 130.000 electores menos.

\begin{tabular}{lrrrrrrr}
\hline $\begin{array}{l}\text { Elecciones } \\
\text { autonómicas }\end{array}$ & 1980 & 1986 & 1990 & 1994 & 1998 & 2001 \\
\hline Nacionalistas & 590.691 & 776.706 & 670.919 & 574.122 & 678.968 & 747.361 \\
\hline No nacionalistas & 288.912 & 355.034 & 321.926 & 441.319 & 555.327 & 658.990 \\
\hline
\end{tabular}

\subsection{El voto de las capitales en contraste con el del resto de los Territorios Históricos.}

La diferente estratificación del voto que existe en las tres capitales de provincia y en el resto de cada uno de los Territorios Históricos es también interesante. Sin embargo, sólo sirve como referencia clara de contraste entre voto urbano y voto rural el dato de Álava. Tanto en Vizcaya como en Guipúzcoa, además de las capitales (Bilbao y San Sebastián), existen otras ciudades de tamaño medio que no permiten hablar de voto rural, como Irún, Tolosa, Baracaldo, Sestao, Getxo, etc. No obstante, la orientación de los electores es, como veremos, algo diferente. 


\begin{tabular}{lllllll}
\hline & $\begin{array}{l}\text { Auton. 98 } \\
\text { Vitoria }\end{array}$ & $\begin{array}{l}\text { Auton. 98 } \\
\text { resto Álava }\end{array}$ & $\begin{array}{l}\text { Gen. 2000 } \\
\text { Vitoria }\end{array}$ & $\begin{array}{l}\text { Gen. 2000 } \\
\text { resto Álava }\end{array}$ & $\begin{array}{l}\text { Auton. 2001 } \\
\text { Vitoria }\end{array}$ & $\begin{array}{l}\text { Auton. 2001 } \\
\text { resto Alava }\end{array}$ \\
\hline PNV & $22371(17,6 \%)$ & $14552(34 \%)$ & $21676(17,4 \%)$ & $13279(34,3 \%)$ & $41521(29,1 \%)$ & $23311(46,8 \%)$ \\
\hline PP & $36435(29 \%)$ & $9035(21,1 \%)$ & $53132(42,3 \%)$ & $13135(33,9 \%)$ & $50248(35,2 \%)$ & $12489(25 \%)$ \\
\hline UA & $12553(10 \%)$ & $1752(4 \%)$ & -- & -- & -- & -- \\
\hline EA & $7227(5,7 \%)$ & $3491(8,1 \%)$ & $5082(4 \%)$ & $2903(7,5 \%)$ & -- & -- \\
\hline UU-EB & $8135(6,4 \%)$ & $1471(3,4 \%)$ & $7877(6,2 \%)$ & $1632(4,2 \%)$ & $9503(6,6 \%)$ & $1927(3,8 \%)$ \\
\hline PSE & $23436(18,6 \%)$ & $5234(12,2 \%)$ & $34132(27,1)$ & $7050(18,2 \%)$ & $32882(23 \%)$ & $6587(13,2 \%)$ \\
\hline EH & $13655(10,8 \%)$ & $6912(16,1 \%)$ & -- & -- & $7363(5,1 \%)$ & $4473(8,9 \%)$ \\
\hline
\end{tabular}

Las elecciones generales de 2000 nos sirven como punto de comparación, porque de algún modo, según hemos ya dicho, PP y PSE se marcaron como objetivo alcanzar unos resultados similares. Como vemos de nuevo en estos cuadros, en número de votos absolutos casi logran su objetivo en Álava, pero, al haberse incrementado notablemente la participación, en términos relativos descienden bastante. Sin duda, la llamada a la abstención de EH en las generales es un factor que influyó notablemente y que quizá debió haberse tenido en mayor consideración al plantear las estrategias electorales.

En todo caso, en Álava es notable la diferencia de porcentaje de voto que el PP y PSE tienen en Vitoria, en comparación con el resto de la provincia. El voto rural alavés es nacionalista, de modo que PNV-EA alcanza en las últimas elecciones casi la mitad de los votos (el $46,8 \%$ ) de las zonas rurales, mientras que en la capital se queda en el $29 \%$, a más de seis puntos del PP. Por el contrario, los populares sólo obtienen el $25 \%$ del voto rural, frente al $35 \%$ en la capital. Además, la diferencia de votos del PP entre los que alcanza en una zona y otra es, en las elecciones de 2001, la más grande de las tres que comparamos, superando los diez puntos. Algo muy parecido ocurre con el PSE, aunque con porcentajes de voto más bajos en general. La distribución de voto de $\mathrm{EH}$ es también desigual, concentrándose su fuerza en mayor medida fuera de la ciudad de Vitoria.

El descenso de voto del PP (con relación a las generales de 2000) es más fuerte en las zonas rurales $(8,9$ puntos) que en la ciudad de Vitoria $(7,1$ puntos), aunque no se corresponde de modo correlativo con el ascenso del PNV, que es mayor en Vitoria (7,7 puntos) que en las zonas rurales ( 5 puntos). Este dato nos lleva a pensar que en la ciudad de Vitoria el voto de $\mathrm{EH}$ se ha desplazado con mayor intensidad hacia el PNV que en el resto de la provincia, $o$ al menos que ha habido más electores procedentes de la abstención. 


\begin{tabular}{lllllll}
\hline & $\begin{array}{l}\text { Auton. 98 } \\
\text { Bilbao }\end{array}$ & $\begin{array}{l}\text { Auton. 98 } \\
\text { resto Vizcaya }\end{array}$ & $\begin{array}{l}\text { Gen. 2000 } \\
\text { Bilbao }\end{array}$ & $\begin{array}{l}\text { Gen. 2000 } \\
\text { resto Vizcaya }\end{array}$ & $\begin{array}{l}\text { Auton. 2001 } \\
\text { Bilbao }\end{array}$ & $\begin{array}{l}\text { Auton. 2001 } \\
\text { resto Vizcaya }\end{array}$ \\
\hline PNV & $65284(30,8 \%)$ & $159258(41,8 \%)$ & $63493(31,1 \%)$ & $158986(37 \%)$ & $91639(38,8 \%)$ & $244306(45,9 \%)$ \\
\hline PP & $56790(26,8 \%)$ & $82371(21,6 \%)$ & $69648(34,1 \%)$ & $107624(25 \%)$ & $71030(30,1 \%)$ & $110374(20,7 \%)$ \\
\hline UA & $301(0,1 \%)$ & $612(0,1 \%)$ & -- & -- & -- & $\cdots$ \\
\hline EA & $10350(4,8 \%)$ & $30746(8 \%)$ & $7705(3,7 \%)$ & $25342(5,9 \%)$ & -- & $\cdots$ \\
\hline IU-EB & $13781(6,5 \%)$ & $28933(7,6 \%)$ & $12243(6 \%)$ & $25434(5,9 \%)$ & $14824(6,2 \%)$ & $28877(5,4 \%)$ \\
\hline PSE & $38364(18,1 \%)$ & $87470(23 \%)$ & $45601(22,3 \%)$ & $103069(24 \%)$ & $43122(18,2 \%)$ & $96562(18,1 \%)$ \\
\hline EH & $25352(11,9 \%)$ & $75025(19,7 \%)$ & -- & -- & $13852(5,8 \%)$ & $48042(9 \%)$ \\
\hline
\end{tabular}

Aunque el nacionalismo moderado cimenta también su victoria en Vizcaya fuera de la ciudad de Bilbao (consigue el $45,9 \%$ de los votos), aquí los datos cambian algo, en parte por lo que decíamos al inicio. En esta provincia hay muchas ciudades industriales de tamaño medio donde el PSE tiene tradicionalmente mucha fuerza, $y$, como puede comprobarse, habitualmente obtiene mayor porcentaje de voto fuera de Bilbao que en la propia capital. Sin embargo, en las últimas autonómicas no ha sido asi, dato que resulta revelador: una parte de su electorado ha respaldado probablemente al PNV, precisamente por ser un voto tradicional, que quizá no veía con buenos ojos el pacto con el PP, por prejuicios ideológicos. Llama la atención el descenso de voto socialista fuera de Bilbao, incluso en comparación con las autonómicas de 1998: baja más de cinco puntos porcentuales, aunque suba en número de votos absolutos.

EI PP, a pesar de incrementar sus votos en números absolutos con relación a las generales, no consigue hacerlo en términos relativos, por las razones reiteradamente expuestas. En este caso, la tendencia descendente es la misma en la ciudad de Bilbao y fuera de ella. También el PP baja en el voto provincial con relación a las autonómicas del 98, casi un punto en términos porcentuales. La coalición PNVEA sube en términos relativos cuatro puntos en Bilbao, y tres en el resto de Vizcaya, con relación a las generales de 2000, lo cual confirma que estamos en un territorio en el que el voto urbano se extiende más allá de la propia capital. Es significativo, sin embargo, que, fuera de Bilbao y con relación a las autonómicas de 1998, los nacionalistas moderados descienden casi cuatro puntos: entonces obtuvieron el $49,8 \%$, y ahora el $45,9 \%$.

Aunque en Álava Izquierda Unida mejora los resultados de 1998 en términos relativos, en Vizcaya lo logra sólo en Bilbao. En ambos casos, sin embargo, se mantiene lejos de otros resultados anteriores. 
En cuanto a $\mathrm{EH}$, con relación a las autonómicas de 1998, pierde en Bilbao exactamente la mitad de su apoyo en términos relativos, $y$ en la provincia algo más todavía. Este resultado no se corresponde con Ios ascensos del PNV, lo cual indica que el voto de $\mathrm{EH}$ no se ha comportado de modo homogéneo, y que, como ya veíamos en Álava, en algunas zonas se ha desplazado con más facilidad que en otras al PNV. En todo caso, el PNV recibe votos también de otros sectores, como antiguos abstencionistas, $y$, en el caso de Vizcaya, muy probablemente, antiguos votantes socialistas. Esto último explicaría el descenso del PSE.

\begin{tabular}{lllllll}
\hline & $\begin{array}{l}\text { Auton. 98 } \\
\text { S. Sebastián }\end{array}$ & $\begin{array}{l}\text { Aut. 98 resto } \\
\text { Guipúzcoa }\end{array}$ & $\begin{array}{l}\text { Gen. 2000 } \\
\text { S. Sebastián }\end{array}$ & $\begin{array}{l}\text { Gen.00 resto } \\
\text { Guipúzcoa }\end{array}$ & $\begin{array}{l}\text { Auton. 2001 } \\
\text { S. Sebastián }\end{array}$ & $\begin{array}{l}\text { Aut. 20 resto } \\
\text { Guipúzcoa }\end{array}$ \\
\hline PNV & $18113(17,1 \%)$ & $70744(23,7 \%)$ & $19860(21,4 \%)$ & $70103(31,8 \%)$ & $46244(38,4 \%)$ & $157201(46,9 \%)$ \\
\hline PP & $27229(25,7 \%)$ & $39883(13,4 \%)$ & $31269(34 \%)$ & $48427(21,9 \%)$ & $32045(26,6 \%)$ & $50747(15,1 \%)$ \\
\hline UA & $131(0,1 \%)$ & $389(1,3 \%)$ & -- & - & $\cdots$ & $\cdots$ \\
\hline EA & $15248(14,4 \%)$ & $41573(13,9 \%)$ & $12504(13,6 \%)$ & $33021(14,9 \%)$ & $\cdots$ & $\cdots$ \\
\hline UU-EB & $5745(5,4 \%)$ & $12999(4,3 \%)$ & $4668(5 \%)$ & $10439(4,7 \%)$ & $7429(6,1 \%)$ & $16302(4,8 \%)$ \\
\hline PSE & $18054(17 \%)$ & $47494(15,9 \%)$ & $21981(23,9 \%)$ & $54750(24,8 \%)$ & $21846(18,1 \%)$ & $52196(15,5 \%)$ \\
\hline EH & $20496(19,3 \%)$ & $82561(27,7 \%)$ & - & - & $12426(10,3 \%)$ & $56983(17 \%)$ \\
\hline
\end{tabular}

También en Guipúzcoa se percibe una gran diferencia entre el voto dentro y fuera de San Sebastián. Los nacionalistas basan su victoria fuera de la capital, donde obtienen un $46,9 \%$ de los votos que, unido al $17 \%$ de $\mathrm{EH}$, otorga una abrumadora ventaja al bloque abertzale: un $64 \%$ del voto, frente al $30,6 \%$ que suman PSE y PP. Las cosas cambian en San Sebastián: PSE y PP alcanzan el $44,7 \%$, frente al $38,4 \%$ de PNV-EA y el $10,3 \%$ de EH. No obstante, la mayoría también es nacionalista.

Con relación a las generales, el PP baja más en San Sebastián $(7,4$ puntos) que en el resto (6,8 puntos), lo cual indica que el PP consigue votos nuevos en los pueblos, mientras que le cuesta alcanzarlos en San Sebastián, donde incluso el ascenso en números absolutos es de apenas 800 votos con relación a las generales, con un índice de participación en la ciudad de 16,5 puntos más. No parece que la abstención de las generales en la capital donostiarra escondiese votos populares, sino que se trataba de un voto nacionalista que, en parte obedeció las consignas de $\mathrm{EH}$, en parte no se vio motivado en el 2000 a acudir a las urnas, pero quizá ahora sí, para defender la tradición nacionalista. 
Este descenso del PP en San Sebastián se corresponde con la subida de la coalición PNV-EA, que alcanza un porcentaje 3,4 puntos superior al de las generales de 2000 , mientras que en el resto de la provincia sólo sube 0,2 puntos: curiosamente es el dato más negativo de la coalición, en términos relativos, ya que no consiguen incrementar su nivel de apoyos que, de todos modos, ya era muy elevado en Guipúzcoa. Como el descenso de EH es bastante similar en San Sebastián y el resto de la provincia, parece probable que, con estos datos en la mano, haya habido trasvase de votos del PP o del PSOE al PNV en la ciudad donostiarra, que explicaria la correlación entre el descenso de los partidos nacionales y el ascenso del PNV.

Llama la atención asimismo el fuerte descenso del PSE fuera de San Sebastián, con relación a los resultados de las generales. Mientras que en la ciudad baja 5,8 puntos, en el resto de la provincia desciende 9,3 puntos. En las generales había conseguido mayor porcentaje de apoyo fuera que dentro de San Sebastián, mientras que ahora se invierten los términos. Este dato hace pensar que, en las zonas industriales, existe un voto socialista en las generales que ha apoyado al nacionalismo en las autonómicas.

\section{ALGUNAS CLAVES EN LOS RESULTADOS DE VITORIA Y ÁLAVA.}

Quizá la mayor sorpresa de las elecciones autonómicas de mayo de 2001 fueron los resultados de los partidos no nacionalistas y, especialmente, del Partido Popular en Álava. Este territorio ha sido siempre el feudo de los populares en el País Vasco, como así lo atestigua el hecho de que sus dos principales instituciones, la Diputación Foral de Álava y el Ayuntamiento de Vitoria estén gobernadas por el PP desde las elecciones municipales de 1999. Este hecho, junto a los magníficos resultados que obtuvo el PP en las elecciones generales de $2000-66.000$ votoshacían prever un nuevo récord de voto popular en las autonómicas.

Para sorpresa de muchos, no fue así. Al menos no resultó tal y como las expectativas que, tras las elecciones, se han considerado exageradamente optimistas, parecían indicar. Pero no fue tampoco un mal resultado: los votos que obtuvo el Partido Popular en las elecciones autonómicas de 2001 en Vitoria constituyen su segundo mejor resultado en la trayectoria electoral de este partido en el País Vasco, tan sólo superado por el que obtuvo en las generales de 2000.

La explicación la podemos deducir de las tablas de resultados que ya hemos comentado: aunque se produce un fuerte descenso en 
porcentaje de voto, la bajada no es tan acusada en número de sufragios. La tendencia general de los resultados en Vitoria es de un ligero descenso del Partido Popular con respecto a las generales en términos absolutos, pero mantiene claramente su posición de primera fuerza, con un apoyo fiel ya consolidado (el PP se mantiene 9.000 votos por delante del PNV). Este fuerte respaldo de los electores vitorianos es el principal fundamento que ha convertido a Álava en el territorio donde cala mejor el mensaje del PP: cuando no es la fuerza mayoritaria en la provincia, como en esta ocasión, se queda a escasos votos de la primera fuerza, en este caso, el PNV.

EI PNV, fruto del aumento de participación y fundamentalmente, del trasvase de votos de EH, mejora mucho sus resultados en las elecciones autonómicas de 2001. A este respecto, hay que considerar que una buena parte de los 13.000 votos que EH obtuvo en las autonómicas de 1998 pudo abstenerse en las generales de 2000 por la petición expresa de su partido. Eso supone que una parte importante del incremento de participación en 2001 con respecto a 2000 se deba a los votos de EH que, en su mitad aproximadamente, van a parar al PNV-EA como voto útil en mayo de 2001.

Ya hemos dicho cómo la mayor parte del voto que se movilizó durante campaña electoral fue nacionalista y eso puede dar pie a pensar que, en Álava, el voto a partidos nacionales estaba totalmente movilizado en las generales de 2000. En consecuencia, la llamada a la participación por parte de los partidos constitucionalistas tuvo, aparentemente, un doble efecto: por un lado, movilizó a la práctica totalidad del electorado del PP y PSOE que votó en las generales de 2000 (si se estudian los resultados en algunos barrios de Vitoria, los votos que pierde el PP en muchas ocasiones los gana el PSOE), lo cual era difícil, pues siempre se produce una cierta desmotivación de este electorado cuando las elecciones son autonómicas y no nacionales.

Pero, por otro lado, el voto nacionalista se movilizó quizá en mayor grado, pues no sólo votaron los electores de EH (que lo habrian hecho en cualquier caso, por su rígida disciplina), sino que muchos de ellos apoyaron al PNV.

Incluso es posible que una parte del electorado nacionalista moderado, o que había optado por la abstención en otras elecciones, se decidiese a participar ante la campaña aparentemente antinacionalista del PP y PSOE: muchos sintieron que su imagen se asociaba a la de los terroristas, y eso les llevó a priorizar un sentimiento defensivo en detrimento de la solidaridad con las victimas de los atentados. 
Resulta especialmente interesante el descenso en un porcentaje considerable de los votos blancos y nulos en estas elecciones. Así, mientras en las generales del 2000 la suma total de estos votos ascendía a 5.985 , es decir, el $4,5 \%$ de los votantes, en las elecciones autonómicas los votos nulos y blancos bajan hasta 2.201 , el $1,5 \%$ de los votantes en las elecciones de 2001. Teniendo en cuenta los resultados, lo más sensato es pensar que el PNV se lleva gran parte de estos votos. Esto puede deberse a dos motivos: 1) que EH ocultara voto en la bolsa de votos blancos y nulos de las elecciones de 2000; 2) que se trate de votos poco ideologizados o concienciados, que se movilizan en esta ocasión hacia el PNV.

La fidelidad de voto es alta en mayo de 2001. Sólo en el caso de EH se produce un amplio trasvase de votos, aunque la magnitud de este cambio afecta extraordinariamente a los resultados globales de las elecciones.

Sin embargo, en lo que se refiere a la fidelidad de voto, cabe subrayar varias cuestiones:

1) Los partidos mayoritarios conservan básicamente sus bolsas de voto: PNV, PP y PSE.

2) La fidelidad de voto es más fuerte en aquellas zonas en las que los votantes se ven obligados a defender de forma más activa su voto. Es clarificador, en este sentido, el caso del PSE, que pierde votos en uno de sus feudos tradicionales en Vitoria, Abetxuko. Algunos de sus votantes en este barrio pueden optar por el PNV como "voto contra" (la posibilidad de un lehendakari del PP) y así el PSE comprueba cómo su número de votos desciende en la zona de la ciudad más reconocidamente socialista. Sin embargo, en las zonas donde gana el PP con mayoría amplía, por ejemplo, el Ensanche, el PSE sube -es verdad que en cifras muy pequeñas- su número de votos. La explicación más lógica es que sus votantes en estas zonas, fuertemente concienciados de la situación que vive el País Vasco, respaldaron aparentemente la actitud del partido en estas elecciones, mientras que en sus feudos tradicionales el voto socialista pudo deberse más a la tradición o al ambiente obrero del barrio.

3) La "infidelidad" de voto de EH probablemente es algo temporal. Los votos que obtiene el PNV de EH serían, a la luz de esta interpretación, un "préstamo" que el PNV debe gestionar si quiere mantener sus resultados, en la seguridad de que el cui- 
dado de esos votos puede suponer un gran desgaste en la gestión nacionalista.

4) Izquierda Unida también mantiene fieles sus votos $y$, aunque en mucha menor medida que el PNV, se beneficia de la «infidelidad" de los votantes de EH: si comparamos los datos se observa que en los colegios donde más crece IU, el PNV progresa por debajo de su media. Eso parece indicar que el aumento de votos de IU se produce a costa de votos de EH que no fueron a parar al PNV.

Al analizar los resultados electorales de Vitoria se comprueba también que los votos que pierde el Partido Popular en estas elecciones con respecto a las generales se trasladan al PNV, aunque en algunos casos van al Partido Socialista. Ante esta evidencia, se plantean fundamentalmente tres cuestiones:

\section{a) El destino de los votos del Partido Popular.}

La participación aumenta cerca del $7 \%$, en 13.129 sufragios. El PP obtiene 2.884 votos menos en las elecciones de 2001 que en las generales de 2000 . El PNV gana 14.563 votos más. Esto supone que votó al PP el $35,25 \%$ de la población y a PNV-EA, el $29,13 \%$. Prácticamente la mitad de la cifra obtenida por PNV-EA se debe, muy posiblemente, a los votantes de EH (13.655 en las pasadas autonómicas, que cumplieron con la llamada a la abstención de su partido en las generales de 2000).

Una visión meramente cuantitativa de los resultados podría conducirnos a pensar que la coalición PNV-EA adquiere los 3.000 votos perdidos por el PP, y los 1.250 perdidos por el PSOE, además de algunos otros que proceden de la mayor movilización nacionalista. En este sentido, es muy posible que una buena parte de los votos perdidos por el PP fueran a la bolsa nacionalista. Los motivos del trasvase serían diversos. En algunos casos, podría tratarse de votos que el PNV "prestan al PP en las elecciones generales (votantes que entre el PP y el PSOE optan por José María Aznar para el Gobierno de España) y que en las autonómicas vuelven al PNV por "conservadurismo". En todo caso, éste es el tipo de electores al que el PP debía haber llegado con su campaña, aunque no lo consiguió.

En otros casos, se debería al "factor gestión": ciudadanos afectados negativamente por la gestión de las instituciones alavesas. Este 
punto, no obstante, es muy difícil de valorar. Los datos no indican que un hipotético desgaste en la gestión municipal o local se traduzca en un castigo a nivel autonómico.

En último término, son votos que también podrian haberse "asustado" ante una combinación de la campaña del PNV -que trató de relacionar un posible Gobierno del PP con un aumento de la crispación social-, y la del PP -como hemos visto, demasiado "agresiva» para algunos electores- a pesar de que, en alguna ocasión anterior, sobre todo en elecciones generales, había apoyado al PP.

\section{b) El origen del voto al PSE en los feudos del PP.}

La comparación entre los resultados de PSE-EE y PP resulta interesante. EI PSE perdió 1.250 votos en estas elecciones. Es decir, le respalda el $23,07 \%$ de los votantes. Se beneficia de algunos votos del PP, aunque estamos hablando de cifras minimas, en los barrios vitorianos tradicionalmente "populares», como Ensanche, San Martín...

Por una parte, en ningún modo resulta disparatado pensar que el voto perdido por el PSOE en los barrios más socialistas no acudió al PP, sino al nacionalismo, en algunos casos por motivos similares a los del trasvase de votos del PP al PNV, pero también como voto útil frente a un lehendakari del Partido Popular.

Por otra, el aumento del voto al socialismo en las zonas más "populares" puede deberse a que se trata de votantes moderados $y$ constitucionalistas, que jamás votarian nacionalismo, pero dieron credibilidad al mensaje nacionalista que vinculaba un posible Gobierno de Jaime Mayor a una crispación social que afectaría a su modus vivendi y prefirieron optar por el mensaje un tanto ambiguo y más favorable al diálogo del Partido Socialista.

EI PSOE en Álava hizo un mensaje anti-nacionalista mucho más claro que en Vizcaya y Guipúzcoa, y eso contribuyó a que el PP no ganara voto útil del PSOE contra el nacionalismo, algo que sí ocurrió en las otras dos provincias. Además, los ciudadanos alaveses no percibieron al parecer grandes diferencias entre el PSE y el PP dada, posiblemente, la colaboración en el Ayuntamiento y en la Diputación; o bien puede que el PSE consiguiera empujar a las urnas a todos sus votantes en las zonas de mayoría popular. 


\section{c) La oportunidad de la coalición del PP con UA.}

La comparación entre las elecciones Municipales y las Europeas del 13 de junio de 1999 es significativa en cuanto al trasvase de votos de UA: sus votantes en las Municipales se dividían prácticamente en partes iguales entre el PSE y el PP. Eso podía hacernos pensar que, si UA optaba por pedir el voto al PP o por integrarse en las listas, sus votos no irían íntegramente a la coalición, sino que algunos se desviarían hacia la opción socialista. Por el contrario, podría sostenerse que, si UA se presentaba de modo independiente, podría agrupar los votos para después uponerlos a disposición" del PP. La incógnita, en este supuesto, estaba en si UA podría superar la barrera del 3\% para alcanzar algún escaño en solitario.

En todo caso, UA optó por concurrir en las listas populares y eso no supuso muchos más votos al PP, lo que sin duda revela una tendencia a la baja en el partido foralista alavés, que va siendo fagocitado poco a poco -y más en estas elecciones- debido a la polarización entre nacionalistas (representados por el PNV) y constitucionalistas (representados por PSE y PP, y no UA, que además quedó sin protagonismo al integrarse en las listas y adoptar la voz de Jaime Mayor).

En resumen, la integración de UA en las listas del PP no sumó votos para el Partido Popular. Por el contrario, pudo incluso restar apoyos entre aquellos votantes nacionalistas moderados que votaron PP en las generales y que consideran a Unidad Alavesa como una opción anti-vasca, con ciertos matices radicales.

Pero, como decíamos al principio, lo verdaderamente peculiar en los resultados de Álava y Vitoria es que, a pesar de constituir el feudo tradicional del PP y contar con gobiernos populares en ambas instituciones, Ayuntamiento de Vitoria y Diputación de Álava, este partido no aumentó ni mantuvo los resultados de las elecciones generales de 2000, aunque mejoró sustancialmente los resultados de 1998.

Con toda la prudencia con la que cabe formular una valoración así, pensamos que una explicación a este resultado podría partir de la idea de que los alaveses no vieron en riesgo sus instituciones en esta convocatoria electoral. En cambio, sí pensaron que la autonomía vasca podía retroceder, como una consecuencia del "efecto péndulo" de la alternativa. En ello pudo haber influido el hecho de que la situación en Álava no es tan dramática como en otros lugares del País Vasco, y quizá esto neutralizó la movilización masiva del voto no nacionalista en el sentido de la campaña -defensa de la libertad y recuperación de la normalidad-. La urgencia de implicarse personalmente parecía menor en Álava, el territorio vasco donde el conflicto se percibe con menor intensidad. 


\section{CONCLUSIONES: LA TAREA PENDIENTE DE RECUPERAR LA LIBERTAD.}

De igual modo que en las encuestas se percibía, como hemos dicho, un estado de opinión completamente diverso en el País Vasco y en el resto de España, la recepción de los resultados fue muy normal en Euskadi, mientras que en el resto de España se consideraba inexplicable. El deseo de alternancia en el País Vasco era mayor fuera que dentro de él.

Sin duda, una de las conclusiones primeras de los resultados era que las expectativas que habían creado en la opinión pública el PP y el PSOE fueron excesivas, $y$ que, como consecuencia de ello, una mejoría de los resultados (como la que tuvo lugar el 13 de mayo) no se consideró como positiva, sino que se le dio mucha mayor importancia a la victoria del PNV-EA y al descenso de $\mathrm{EH}$, mientras que el bloque PPPSE parecía el gran derrotado. En realidad, con los números en la mano, esto no fue así, pero la opinión pública lo valoró mayoritariamente de esta forma.

En cuanto a los motivos que dieron lugar a este resultado, que confirmó la confianza de la mayoría de los vascos en el bloque nacionalista moderado, se pueden señalar varios:

a) Una buena parte de los electores ha otorgado mayor importancia al bienestar socio-económico de la mayoría de los vas$\cos$ que a los problemas de supervivencia de una minoría amenazada por ETA. En este sentido, la campaña del PNV, victimista por un lado, y resaltando los logros económicos por otro, tuvo éxito a juzgar por el resultado final. Existe un sector muy amplio de la sociedad vasca que no cuestiona la hegemonía nacionalista, y sin embargo se ha constatado, una vez más, que los uperseguidos son una minoría, no mayor a la de los comunistas y masones en la España franquista de los cuarenta e incluso a los judíos en vísperas del ascenso nazi al poder ${ }^{27}$. Esta actitud ha sido criticada, de insolidaria, por numerosos políticos y analistas.

b) Según los sociólogos, existe además un apoyo no nacionalista al PNV que, a pesar del mensaje más radical del nacionalismo en esta campaña (asumiendo la línea "soberanista»), le ha

27 De Blas Guerrero, Andrés, "Las elecciones vascas del 13-M", en Temas para el Debate, julio 2001, núm. 80, p. 54. 
vuelto a dar su apoyo. Éste sería un sector que probablemente vota PSE o PP en las generales, pero continúa votando PNVEA en las autonómicas. Se trata de la manifestación de una confianza en la capacidad de gestión del nacionalismo moderado que pasa por encima de las preferencias políticas de estos electores. Quizá de este modo estén buscando una mayor integración en la sociedad vasca, para ser "ciudadanos de primera" como los nacionalistas ${ }^{28}$. En todo caso, es un dato preocupante, puesto que también este sector da mayor importancia a los factores económico-sociales que al terrorismo.

c) La valoración con la que partían los dos candidatos principales, Ibarretxe y Mayor Oreja, era muy distinta. Mientras que este último era el candidato peor valorado, Ibarretxe era el mejor valorado incluso en algunos ámbitos no nacionalistas. Sin duda influía también en este dato la «tupida red identitaria y de intereses clientelares ${ }^{29}$ de la que gozaba Ibarretxe. Además, Ibarretxe representaba los intereses locales, mientras que Mayor era un candidato de Madrid, a pesar de ser vasco, puesto que quizá tardó demasiado tiempo en dejar el Ministerio del Interior y, en todo caso, se le criticaba una cierta imagen de político "de ida y vuelta" ${ }^{30}$.

d) Los electorados nacionalista y no nacionalista se han comportado con gran fidelidad a sus partidos. Sin embargo, a pesar de que se ha dicho que en estas elecciones use ha vuelto a reproducir el patrón de comportamiento electoral/ ${ }^{31}$ de otras convocatorias, en el sentido de que una parte del electorado vota en las elecciones generales pero no lo hace en las autonómicas, creemos que no ha sido exactamente así. Lo que ha ocurrido es que el PP y el PSOE han conseguido movilizar a casi el mismo número de electores que en unas generales, pero el nacionalismo movilizó, por su parte, a una buena porción de electores que, quizá por pereza o cansancio, no había acudido a las urnas en convocatorias anteriores. Los ciudadanos que se sintieron empujados a votar en los últimos días, cuando la campaña se radicalizó y el nacionalismo

\footnotetext{
cit., p. 57.

30 Ibidem.

31 Ibidem.
}

De Blas Guerrero, Andrés, "Las elecciones vascas del 13-M", op. cit., p. 55. LLERA, F.J., "Cambio político en Euskadi: Entre Lizarra y Ajuria-Enea", op. 
explotó su papel de víctima, dirigieron su apoyo mayoritariamente a la coalición PNV-EA. Por eso, si no se hubiera producido este "plus" de participación como consecuencia de las jornadas finales de la larga campaña electoral, probablemente habría sido acusado por los partidos nacionalistas, mientras que el PP y el PSE habrian estado más cerca de la victoria, al tener su electorado básicamente asegurado desde unas semanas antes de la jornada electoral.

e) El bloque nacionalista y el no nacionalista se mantienen bastante estables con respecto a convocatorias anteriores. La suma del PP-UA y del PSE es la misma que antes, perdiendo un escaño los socialistas, que ganan los populares. La suma de los nacionalistas desciende en un escaño, que gana IU. Los que logra esta última coalición no pueden encuadrarse en ninguno de los dos bloques, aunque quizá están más cerca del bloque nacionalista.

f) PP-UA y PSE consiguen sus objetivos en Guipúzcoa, pero no en Álava, donde se quedan a dos escaños de lo que quizá esperaban. Otros dos escaños los pierden el PSE en Vizcaya por unos pocos votos, y el PP en Guipúzcoa por algunos más. Si hubieran logrado estos cuatro, harían un total de 36 , mientras que PNV-EA pasaría a tener 29. Como se puede comprobar, un mínimo número de votos habría hecho cambiar bastante el resultado. Nos parece además que con estos datos sobre la mesa, puede sostenerse que, por primera vez, en estas elecciones se ha visto posible la articulación de una alternativa ${ }^{32}$. Los partidos no nacionalistas han perdido el miedo a ponerse de acuerdo frente a los postulados naciona-

32 En este sentido, resulta muy clarificador el artículo de RUBIo LLORENTE, F., "Derrotados pero no confundidos", en El País, sábado, 9 de junio de 2001. Después de criricar a quienes han considerado un error la estrategia de populares y socialistas en las elecciones vascas, en defensa de la Constitución y el Estatuto, concluye que usin poner en cuestión el deseo sincero de los nacionalista demócratas de acabar con el terror, la debilidad de las razones con las que se argumenta el error 'constitucionalista' y la conveniencia de remediarlo mediante el regreso a una política cuya ineficacia para reducir la tensión nacionalista ha quedado acreditada por una experiencia de doce años llevan a pensar que no ha habido error alguno; que es la razón, y no el prurito irracional de mantenella y no enmendalla, la que aconseja hacer de la defensa de la Constitución y el Estatuto el objetivo primordial y común de cuantos ven en esa fórmula, hoy por hoy, la única capaz de asegurar la convivencia en paz de todos los vascos». 
listas más radicales, y han obligado al PNV a adoptar una actitud defensiva.

g) EI PNV consigue todos sus objetivos, y probablemente más de los que se había planteado. Concentra el voto nacionalista más que nunca (por encima del $80 \%$ del voto total de este sector), mejora en votos (6,5 puntos) y escaños (7), y es la primera fuerza en todos los Territorios Históricos, siendo especialmente significativa su victoria en Álava, que no esperaba nadie.

h) Podría decirse, en fin, que en estas elecciones han obtenido mejores resultados los partidos que han buscado la equidistancia: el PNV ha intentado mostrarse como la opción a medio camino entre EH y PP. IU se ha mostrado como la opción intermedia entre EH y PNV Y, con esta estrategia, ambos han conseguido votos "prestados". Los votantes menos ideologizados han interpretado como centralidad la equidistancia del PNV entre la opción radical y la constitucionalista. EI PNV se ha presentado como una pista de aterrizaje del voto de castigo a ETA que ha sufrido EH.

El nuevo gobierno vasco, que inicialmente ha estado formado sólo por PNV y EA, aunque luego se ha incorporado IU, tiene por delante un reto complicado. Debe administrar su victoria de manera que se den pasos hacia la pacificación definitiva de Euskadi. Necesitará para ello demostrar con hechos un cambio de actitud, de modo que la acción política nacionalista se parezca más al mensaje moderado de Ibarretxe en la campaña que al radical de Arzallus o Egibar. Sin embargo, en el texto del pacto de gobierno entre PNV y EA, no se ha mostrado de modo evidente que su interés prioritario sea el de acabar con el terrorismo. Por el contrario, el texto hace referencia a términos típicos de la estrategia de unidad nacionalista que comenzó con la tregua de ETA, como el del respeto al "ámbito vasco de decisión", o incluso se recoge de manera literal la expresión "derecho de autodeterminación», al incorporar una declaración aprobada en este sentido por el Parlamento vasco en $1990^{33}$. Tomar la autodeterminación como meta principal supone retornar a la peligrosa identificación de objetivos entre el nacionalismo moderado y el nacionalismo violento, sin condenar expresamente los medios empleados por este último. 
Desde el punto de vista social hace falta también que los movimientos ciudadanos no se detengan, y que el sector de la sociedad que, a pesar de la realidad terrorista, ha preferido renovar su confianza en los nacionalismos, demuestre también su responsabilidad, exigiendo resultados al nuevo Gobierno. Para evitar cualquier género de dudas sobre una hipotética falta de solidaridad ciudadana, deberia producirse una movilización moral de la sociedad vasca en defensa activa de la dignidad y la libertad de los ciudadanos que son víctimas del acoso terrorista. El Gobierno Vasco, desde el punto de vista institucional, debería encabezar esta movilización. Sin embargo, los primeros signos no parecen anunciar ningún cambio, y por ello es incierto lo que puede suceder en los próximos años de esta legislatura, con un Gobierno vasco obligado a contentar a unos y a otros.

Se ha dicho recientemente que «urge la unidad democrática para concertar lo fundamental y urge un Gobierno mayoritario que lo haga con eficacia política y no se conforme con administrar un presupuesto ${ }^{34}$. Así se lo ha querido exigir el pueblo vasco con su masiva participación electoral. Aunque el Gobierno no dispone de la mayoría absoluta en el Parlamento, sí tiene suficiente respaldo como para encabezar, si es su voluntad política, el camino de la pacificación. Ahora bien, sólo será posible alcanzar la auténtica paz si, al mismo tiempo, se recupera y garantiza el derecho de todos los ciudadanos de Euskaki a expresar sus ideas y opiniones. La tarea consiste, por lo tanto, en lograr la paz desde la libertad.

34 LLERA, F.J., "Cambio político en Euskadi: Entre Lizarra y Ajuria-Enea», op. cit., p. 58. 